\title{
Ein heizbarer Objecttisch und seine Verwendung bei Untersuchungen des Blutes.
}

\author{
Vom
}

\section{Herausgeber.}

Hierzu Taf. I und II.

Die Untersuchungen, welche ich über den Einfluss einer über die Zimmerwärme gesteigerten 'Temperatur auf die Körpersubstanz der Rhizopoden und auf die Rewegungen des Protoplasina der Pflanzenzellen anstellte, über welche ich in meiner Schrift "Das Protoplasma der Rhizopoden und der Pflanzenzellen, Leipzig 1863“ berichtet habe, brachten mich auf den Gedanken, einen Apparat zu construiren, mit Hülfe dessen es möglich würde, rlas Object bei beliebigen messbaren; zul- und abnehmenden, sowie auch constant zu erhaltenden Temperaturgraden zu beobachten. Das Bedürfniss, mikroskopische Präparate während der Beobachtung zu erwärmen, ist von manchem Mikroskopiker empfunden worden ${ }^{1}$ ), wie genügsam man aber in seinen

1) Ich erwähne hier als eines der ersten Versuche, das Object während der Beobachtung zu erwärmen, der Experimente meines Vaters über den Einfluss höherer Temperaturgrade auf äie Schnelligkeit der Molekularbewegung (C. A. S. Schultze, Mikroskop. Unters. über des Herrn Rob. Brown Entdeckung lebender selbst im Feuer unzerstörbarer Theilchen in allen Körpern und über Erzengung der Monaden, Freiburg 1828, p. 17). Nein Vater bediente sich der zur Beleuchtung opaker Gegenstände den Mikroskopen beigegebenen Convexlinse als Brennglas. Aus neuester Zeit liegen einige hierhergehörige Versuche vor von Schweigger-Seidel (Virchow's Archiv.Bd. XXVII, p. 486) und von Rollet (Sitzungsber. d. Akad. d. Wiss. zu Wien Bd.L, 1864. Ueber die successiven Veränderungen, welche electr. Schläge an d. rothen Blutkörperchen hervorbringen. Sep. p. 15). Beide benutzten einen gefensterten Streifen von Eisenblech, der an einer über den Objecttisch hinausragenden Seite erwärmt wurde. 
Ansprüchen gegenüber den zu verwendenden Apparaten war, lehren die bezüglichen Angaben und die neuesten Handbücher der Mikroskopie ${ }^{1}$ ). In keinem Falle war auch nur auf eine ungefähre Bestimmung des Temperaturgrades durch Thermometer Rilcksicht genommen. Ohne eine solche war aber jeder Erwärmungsapparat für unsere Zwecke so gut wie unbrauchbar.

Der heizbare.Objecttisch, welchen ich von dem Mechaniker Herrn Geissler hierselbst anfertigen liess, und welcher sich als ein sehr wichtiges Hülfsmittel bei vielen Untersuchungen bewährt hat, ist dazu bestimmt, auf den gewöhnlichen Objecttisch eines Mikroskopes aufgesetzt zu werden, den er etwa um 1 Centimeter erhöht (vergl. Taf. I, Fig. 1, wo derselbe von unten in halber natürlicher Grösse abgebildet ist). Derselbe besteht aus einer ungefähr hufeisenförmigen Messingplatte von 1-2 Millimeter Dicke. Der mittlere Theil hat die Ausdehnung und Form eines recht grossen gewöhnlichen Objecttisches und verlängert sich nach beiden Seiten in $3 \mathrm{Cm}$. breite Arme, welche nach kurzem Verlaufe in rechtem Winkel nach yorn umbiegen und von da an noch eine Länge von $17-20 \mathrm{Cm}$. besitzen. Unter ihnen brennen behufs der Erwärmung des Objecttisches Spirituslampen. Die Länge der Arme ist so gewählt, dass bei Erhitzung ihrer Enden durch kleine Flammen die Mitte des Objecttisches ungefähr Körperwärme, also $3 \check{o}-40^{n} \mathrm{C}$. annimmt. Diese Mitte ist von kleiner Blendungsöffinung durchbohrt, welche bei der Befestigung des heizbaren Objecttisches jedesmal genau zu centriren ist. An die untere Seite des Tisches sind seitlich zwei von vorn nach hinten laufende viereckig prismatische Holzleisten (a a) befestigt, mittelst deren er auf dem eigentlichen Objecttisch des Mikroskopes ruht und durch welche eine Mittheilung der Wärme an letzteren, zugleich eine Be-

1) Man vergl. u. A. Harting, das Mikroskop, deutsch von Theile, 1859, p. 429 . Sch a cht, das Mikroskop, 3. Auf. 1862, p. 79 . Beale, how to work with the microscope, 3 edit. 1865, p. 129, Taf XXXV, Fig. 158. Frey übergeht in seinem schätzbaren Buche über das Mikroskop, Leipzig 1863, die künstliche Erwärmung gänzlich mit Stillschweigen. Chevalier's pyrochemischer Apparat, dessen Harting a. a. O. Erwähnung that, ist nur an dem Universalmikroskop von Chevalier anwendbar, welches so gestellt werden kann, dass der Tubus und die Objectivlinsen unter den Objecttisch zu stehen kommen. Er findet sich abgebildet bei Chevalier, Des microscopes et de leur usage, Paris 1839, Pl.4, fig. 3 bis und bei $J_{\mathfrak{u} l}$. Vogel, Anleitung z. Gebrauche des Mikroskopes und der zoochemischen Analyse, Leipzig 1841, Taf II, Fig. 6. 
rührung des in der Mitte unter dem Tisch angebrachten Thermometerkastens mit dem unteren Objecttisch verhindert wird. Das Thermometer besteht aus einem spiralgewundenen, die Blendungsöffnung unkreisenden Quecksilberbehälter von zwei vollständigen Spiraltouren, aus welchem sich die Thermometerröhre nach vorn erhebt, um an eine aus starkem Messing gearbeitete, durch Schrauben an den Tisch befestigte Skala (c) zu gelangen, deren vorderer Seite sie anliegt. Die Skali steht schief nach vorn und aufwärts, so dass der Stand des Quecksilbers während der mikroskopischen Beobachtungen leicht abgelesen werden kamn, und ist in ganze Grade nach Celsius getheilt. Die Quecksilberspirale muss der unteren Fläche des messingnen 'Tisches womöglich mit einer abgeplatteten Fläche genau anliegen, um deren Temperatur schnell aufzunehmen, und ist in einen niedrigen Kasten von Messingblech eingeschlossen, welcher eine Verletzung derselben hindert, vor Abkühlung bewahrt, und indem er die Temperatur des Objecttisches annimmt, das Thermometer auch von unten her erwärmt. In die Mitte des Kästchens ist eine conisch ausgedrehte, innen geschwärzte Blendung eingesetzt etwa von den Dimensionen der $\mathrm{Hartna}$ ck'schen Cylinderblendungen.

Zur Befestigung des heizbaren Tisches kamn man sich der an den Hartnack' und Zeis'schen Mikroskopen im Objecttisch angebrachten, zur Aufnahme der selten gebrauchten Messingklemmen bestimmten beiden Oeffnungen bedienen. Entsprechend der Entfernung derselben von einander und mit genauester Berücksichtigung der Centrirung der Blendungsöffnung lässt man in den heizbaren Tisch ein Paar in die gedachten Löcher passender Stäbe einschrauben. Oder man benutzt Klemmschrauben, wie sie Herr Ge issler dem Apparat beigiebt, um den Tisch in der Gegend von e e an den Objecttisch anzuschrauben. Hierbei ist jedoch zu berücksichtigen, dass die auf die obere Seite des Tisches übergreifenden Blätter der Klemmschrauben bei Verschiebung der Objectträger sehr hinderlich werden können, desshalb passend in Ausschnitte der Messingplatte eingelassen werden. Natürlich muss der Objecttisch des Mikroskopes so breit sein, dass der heizbare Tisch mittelst der Holzleisten a a auf ihm ruhen könne.- Die Entfernung dieser letzteren von einander beträgt circa $6 \mathrm{Cm}$., so dass ein $6-7 \mathrm{Cm}$. breiter Objecttisch wie die Hart$\mathrm{nack}$ ' und die grösseren wie mittleren Zeis'schen Instrumente ihn haben, keine Hindernisse der Befestigung bietet.

Die Beobachtung feuchter Objecte bei erhöhter Temperatur 
bringt natürlich eine schnelle Verdunstung der Flüssigkeit mit sich, in welcher das Object enthalten ist. Um die daraus entstehenden Unbequemlichkeiten und das Object stïrenden Eintlüsse zu vermeiden, beobachtet man in der von v. Reck ling ha u sen empfohlenen fe uch ten Ka mmer ${ }^{1}$ ). Die Einrichtung, wie ich, ganz im Anschluss an v. Recklinghaus.en, dieselbe benutze, ist in Fig. 2 auf Taf. I abgebildet und besteht 1) aus einem abgesprengten unteren Stück eines Lampencylinders, dessen oberer engerer Theil genau der Dicke des Tubus entspricht, ohne jedoch den auf- und absteigenden Bewegungen des letzteren hinderlich zu sein, 2) aus einem Objecttrüger von dü̈nem Spiegelglas von $7 \mathrm{Cm}$. Lünge und $6 \mathrm{Cm}$. Breite. Auf diesem ruht der 5 Cm. in Durchinesser haltende untere Theil des Lampencylinders mit glatt polirtem Rande. Ist das Präparat in der Mitte des Objectträgers angefertigt und der Tubus in die obere Oeffnung des Lampencylinders gesteckt, wie die Figur zeigt, so bleibt zwischen Präparat und Rand des Glascylinders Raum genug zur Verschiebung des Präparates, welche nur bei Anwendung ungewöhnlich grosser Deckgläser nach dieser oder jener Richtung gehindert sein könnte. Um den inneren Raum der Kammer mit Wasserdunst dauernd zu erfüllen genügt es, vor dem Anfang der Beobachtung einen doppelten Streifen Fliesspapier mit destillirtem Wasser benetzt der inneren Oberfläche des Lampencylinders anzulegen, welchem man jedoch passend nur die Länge von Dreiviertel des Umkreises giebt, um ein Viertel der Glaswand zum ungehinderten Einblick in die feuchte Kammer frei zu behalten. Durch ein Beschlagen der unteren Objectivlinse mit Wasserdampf, welches man erwarten könnte, bin ich bei Beobachtungen mit starken Vergrösserungen und bei Anwendung eines Deckglases nie gestört worden. Durch die Anwendung der feuchten Kammer wird nebenbei jeder die Temperatur des Objectes möglicher Weise beeinflussende Luftzug abgehalten, und empfiehlt sich die Einrichtung demnach auch als trockne Kammer, für den Fall es sich um Beobachtung trockner Objecte bei bestimmten Temperaturgraden handelte.

Nach dem oben Angeführten wird der Tisch des Mikroskopes durch den neuen Apparat um etwa $1 \mathrm{Cm}$. erhöht, folglich die Entfernung zwischen Spiegel und Object um ebensoviel vergrössert. Da diese Entfernung, wie die einfachsten Controllversuehe lehren, nicht gleichgültig für die Helligkeit und Klarheit des mikroskopischen

1) Virchow's Arehiv etc. Bd. XXVIII, I863, p. 162. 
Bildes, namentlich bei Anwendung sehr starker Vergrösserungen ist, so wird es nöthig, falls bei guter Form der Blendungseinrichtung die Schärfe des Bildes zu wünschen übrig lassen sollte, den Spiegel des Mikroskopes um so viel höher zu rücken, als der Objecttisch erhöht worden ist.

Man überzeugt sich nun leicht durch Heizversuche mittelst kleiner unter die Arme des heizbaren Tisches gestellter Spirituslampen, dass die Temperatur der Mitte des Objecttisches je nach der Entfernung der Lampen von derselben auf höheren oder niederen Graden nahezu constant erhalten werden kann. Fur die Körpertemperatur, bei welcher anhaltend fortgesetzte Beobachtungen auszuführen vielfach Veranlassung vorliegt, genügen kleine unter die äussersten Enden der Arme gesetzte Lampen, an denen man regulirt, bis das Thermometer $30-40^{\circ} \mathrm{C}$. dauernd anzeigt. Um diesen Effect sicher zu erreichen, ist es gerathen, bei den angegebenen Längendimensionen die Dicke des Objecttisches nicht über $1 \frac{1}{2} \mathrm{Mm}$. zu wählen. Bei grösserer Dicke müsssten die $\Lambda$ rme noch um einige Centimeter verlängert werden.

Aber entspricht die an der skali abgelesene Temperatur wirklich derjenigen der genaulen Mitte des Objecttisches, also derjenigen des mittleren Theiles des mikroskopischen Präparates, welches jedesmal im Gesichtsfelde liegt?

Um diese Frage beantworten zu können, bedarf es einiger Controllversuche. Liegt der Quecksilberbehälter des Thermometers der vuteren Fläche des Objecttisches möglichst genau an, wovon man sich durch .Abschrauben des ihn bergenden Kästchens leicht überzengen kann, und ist ferner die Blendungsöffnung möglichst klein gewählt ${ }^{1}$ ), so ist bei langsamem Heizen eine bedeutende Differenz im Gange des Thermometers und der Temperatur des Objectes nicht zu erwarten, wie ich mich nach Prüfung einer Anzahl von Geissler gefertigter Apparate überzeugt habe. Dennoch wird jeder Apparat besonders zu reguliren sein. Zur Prüfung empfiehlt sich die Beobachtung des Schmelzpunktes von Fetten, von denen man im flüssigen Zustande ein mikroskopisches Präparat anfertigt, nachdem man vorher den Schmelzpunkt auf andere Weise genau bestimmt hat. Ich bediente mich zunächst des Paraftins, und liess von dem-

1) Es würde mit wenig Umständen verbunden sein, verschieden weite Blendungen nach Art der Hartnacls'schen zum Einlegen und Wechseln anfertigen zu lassen. 
selben ein wenig im Hussigen Zustande in ein Hairröhrchen eintreten. Nach dem Erkalten brachte ich dasselbe neben ein Thermometer, dessen Gang mit dem meines heizbaren Objecttisches ubereinstimmte, in ein Wasserbad, clessen Temperatur langsam bis zur Verflüssigung des Paraffins gesteigert wurde. Die im Momente derUmwancllung des undurchsichtigen festen Paraffinfadens in einen durchsichtigen, flüssigen beobachtete Temperatur wurde notirt, sie betrug bei dem von mir verwandten Paraffin nach mehreren übereinstimmenden Versuchen $51-52^{\circ} \mathrm{C}$. Von demselben Paraffin wurde nun ein Tropfen auf dem Objectträger unter Deckgläschen und nach dem Erkalten zur mikroskopischen Beobachtung auf den heizbaren Objecttisch gebracht, vor Luftströmungen aber durch die oben beschriebene Glaskammer geschützt. Beim Heizen gebrauchte ich die Vorsicht, die Temperatur nicht zu schnell zu. steigern, namentlich zwischen 40 bis $50^{\circ}$ ein schnelleres Auwachsen der Temperatur zu vermeiden, damit eine gehörige Ausgleichung stattfinden könne, $d . h$. ich rechnete auf die Steigerung von 40 auf $50^{\circ}$ die Zeit von mindestens 5 Minuten. Ich nenne eine solche Steigerung langsames Heizen. Gewöhnlich traf es sich nun, dass ich die Temperatur bis 53 oder $54^{n}$ wachsen lassen musste, ehe eine Verflüssigung des Paraffins in der Mitte des Objecttisches eintrat. Während am Rande des Deckglases das Fett schon geschmolzen war, persistirten in der Mitte über der Blendungsöffnung die Krystalle noch einige Zeit, und es begegnete wohl, dass wenn eine verflüssigte Stelle vom Rande her in das Gesichtsfeld geschoben wurde, hier sofort Krystallisation eintrat, trotzdem das Thermometer auf $53^{\circ}$ stand. Diese Ungleichheit wuchs sehr auffallend mit derVergrösserung der Blendungsöffnung, nahm dagegen ab mit der Verkleinerung derselben. Es erhellt, dass die durch die Blendung von unten her an den Objectträger gelangende kältere Luft die Uebereinstimmung im Gange des Thermometers und in der Temperatur des Objectes stört, so dass es hiernach geboten ist, die Blendungsöffnung $\mathrm{möglichst} \mathrm{klein} \mathrm{zu} \mathrm{wählen.}$

Es lässt sich nicht verkennen, dass die schlecht leitende Paraffinschicht unter dem Deckgläschen einer gleichmässigen Vertheilung der Wärme minder günstig sei, als ein in Wasser oder einer wässerigen Flüssigkeit beobachtetes mikroskopisches Präparat gewöhnlicher Art. Um den Versuch daher in günstigerer Weise vergleichbar zu machen, fertigte ich durch Schütteln erwärmten Gummischleimes mit Hlïssigem Paraftin eine Emulsion an, in welcher sich nach ihrem Er- 
kalten massenhaft kleinste Paraffinkügelchen vertheilt fanden. Diese, zum Theil nicht grösser als ein Blutkörperchen und von wässeriger Flüssigkeit umgeben, bildeten nun ein vortreftliches Probeobject, da an ihnen der Uebergang aus dem starren, krystallinischen in den Hüssigen Zustand fast momentan vollendet ist. Als ein solches Prïparat in der feuchten Kammer langsam erwärmt wurde, zeigte sich, dass auf demselben Objecttisch, auf welchem das Schmelzen des Palaftins vorher bei $53-54^{\circ}$ beobachtet worden, die Vertlüssigung jetzt bei $51-52^{\circ}$ eintrat und dass ein Untersehied in der Temperatur der Mitte des Präparates' und der Ränder, vorausgesetzt dass eine recht kleine Blendungsöffnung angewandt worden, kaum mehr zur Wahrnehmung kam. Hiernach ist also jedenfalls die Pröfung mittelst in Wasser suspendirter kleiner Paraffintheilchen der erstbeschriebenen Methode bei weitem vorzuziehen.

Nicht alle Exemplare des heizbaren Objecttisches, welche durch meine Hände gegangen sind, zeigten dieselbe Uebereinstimmung. Der häufigere Fehler war, lass das Thermometer die 'lemperatur etwas früher anzeigte, als das Präparat, so zu sagen vor Uebelstande ist durch das Einschieben eines Blättchens dickeren oder dünneren Papieres zwischen Thermometer und untere Seite des Objecttisches abzuhelfen. Auch der ungekehrte Fall kam vor. Das Paraffin war geschmolzen, während das Thermometer erst $45^{\circ}$ anzeigte. Als Grund der Differenz stellte sich heraus, dass die Spirale des Thermometers der Metallfläche des Objecttisches nicht dicht anlag. Um eine zu schnelle Erwärmung des Thermometers zu verhindern, liess ich statt des zum Schutz des Thermometers dienenden Kästchens von Messingblech ein solches von $\mathrm{Hol} \mathrm{z}$ anfertigen. Das Thermometer ging jedoch wegen der mangelnden Erwärmung von unten in diesem Falle so bedeutend nach, dass ich diese Art der Construction aufgeben musste.

Nach dem Obigen wird man in den meisten Fällen im Stande sein, die etwaigen Mängel des heizbaren Objecttisches zu corrigiren. Natürlich kann man sich statt des Paraffins mancherlei anderer Sübstanzen bedienen. Ich wandte $z$. B. noch Stearinsäure an, deren Schmelzpunkt bei $52-53^{\circ} \mathrm{C}$. lag. Wir werden ferner weiter unten hören, dass die rothen Blutkörperchen in jedem Tropfen frischen Blutes ein vortreffliches Probeobject für den heizbaren Objecttisch darstellen.

Ich komme nach dieser Beschreibung des neuen und bei vielen 
mikroskopischen Untersuchungen mit Vortheil zu verwendenden Apparates zum zweiten Theile meiner Arbeit, zur Beschreibung einiger Beobachtungen an lebendigen Geweben, bei denen ich mich des heizbaren Objecttisches bediente. Die erste Anwendung machte ich von clemselben, um die geformten Elemente des menschlichen Blutes genauer zu studiren, und so mögen denn auch die auf diese Flüssigkeit bezüglichen Beobachtungen hier an erster Stelle folgen. Ich verspare es auf einen zweiten Aufsatz, über die anderweitigen Versuche, die ich anstellte, zu berichten.

Es ist in der That erstaunlich, dass bisher kein Mikroskopiker auf den Gedanken gekommen zu sein scheint, dis Blut des eigenen Körpers oder anderer warmblütiger Wesen methodisch bei Körperwärme zu untersuchen. Nehme ich einige Angaben von Klebs ${ }^{1}$ ), von Rollet ${ }^{2}$ ) und von Beale ${ }^{3}$ ) aus, welche sich auf den Einfluss gesteigerter 'Temperatur auf das Blut des Menschen und einiger Thiere beziehen, aber keinen Anspruch darauf nachen, die Erscheinungen, wie sie das lebendige Blut bietet, genauer zu zergliedern, so fehlen, so viel ich weiss, bezügliche Angaben gïnzlich. Auch die genannten Forscher beschränkten sich auf Beobachtungen an rothen Blutkörperchen, von denen $\mathrm{Klebs}$ meldet, dass er die schüsselförmigen, zu Geldrollen gruppirten des Menschenblutes und des Blutes einiger Thiere bei Erwärmung auf die Temperatur des Körpers unter Verhinderung der Verdunstung zackig werden sah, welche Veränderung er aus einer lebendigen Contractilität der Substanz des Blutkörperchens ableitet. Die Art der Erwärmung beschreibt uns Klebs in seiner kurzen Mittheilung nicht. Rollet giebt an, dass er mit Hülfe eines auf den Objecttisch des Mikroskopes auf Korkunterlagen ruhenden Streifen Eisenbleches, der an einer Seite den Objecttisch überragend hier durch eine Spirituslampe erwärmt wurde ${ }^{4}$ ), succes-

1) Centralblatt f. d. medicin. Wissenschaften 1863. No. 54.

2) Sitzungsber. d. Akad. d. Wiss. zu Wien, 14. Juli 1864. Ueber die successiven Veränderungen, welche electr. Schläge an rothen Blutkorperchen hervorbringen. Separatabdr. p. 15.

3) Quarterly journ. of microsc. science, Jan. 1864. No. XII. Transact. of the micr. society p. 36 .

4) Ich bemerke hier, dass mein heizbarer Objecttisch, welcher ein vervollkommneter Rollet'scher genannt werden kónnte, in keiner genetischen Beziehung zu letzterem steht. Ich zeigte den meinigen in der hiesigen niederrheinischen Gesellschaft für Natur- und Heilkunde schon am 8. Juni 1864 (vergl. die Sitzungsberichte, reproducirt in der Berliner klinischen Wochen- 
sive Veränderungen der Frosch- und Säugethierblutkörperchen beobachtet habe, welche unter Uebergängen aus der Dumbbell- und Eiform zur Kugelform führten, ganz ähnlich wie solche Veränderungen durch heftige electrische Schläge entstehen. Durch Anwendung des Wasserbades überzengte sich Rollet dann weiter, dass der Eintritt der Formveränderungen zwischen 45 und $54^{\prime \prime} \mathrm{C}$. fällt und bei $60^{\circ} \mathrm{C}$. vollendet ist, für die Süngethierblutkörperchen lag die Temperatur niedriger, bei $40-45^{\circ} \mathrm{C}$. B e a l e endlich, welcher am angeführten Orte über die Natur der rothen Blutkörperchen handelt und, wie es scheint, ohne von den Arbeiten Rollet's eine Kenntniss zu haben, zu dem Resultate kommt, diss den rothen Blutkörperchen eine Membran ummöglich zugesprochen werden könne, erwähnt, duss er bei Anwendung einer bis $100^{n}$ gesteigerten Temperatur aus den Blutkörperchen des Frosches und Menschen Fülen und Kügelchen hervortreten sah, welche sich in lebhafter Molekularbewegung befanden. B e ale warnt, diese Fïden, welche sich auch abgelöst noch bewegen, und von denen er meint, dass sie auch unter gewissen Unständen im Leben entstehen könnten, mit Monaden (Bacterien) zu verwechseln, welche sich bei gewissen Krankheiten vor dem tödtlichen Ausgange entwickeln sollen.

Mein Hauptaugenmerk bei Beobachtungen des Blutes war zunächst auf das Verhalten der farblos en Blutkörperchen gerichtet, von denen sich von vorn herein annehmen liess, dass sie bei ihrer Neigung zu selbstständigen Pewegungen, wie wir sie bekanntlich durch Lrieberkühn's sorgfältige Beobachtungen ${ }^{1}$ ) zuerst genauer kennen gelernt haben, durch Temperaturdifferenzen des umgebenden Mediums in ähnlicher Weise beeinflusst werden würden, wie dies von dem Protoplasma der Pflanzenzellen vor mir und Andern nachgewiesen war ${ }^{2}$ ). Der Erfolg entsprach vollständig den Voraussetzunschrift 1864, No. 36). Rollet machte die citirte Mittheilung am 14. Juli 1864 der Akademie zu Wien. Ich benutze diese Gelegenheit, einen in dem Sitzungs. bericht in der gedachten Nummer der klinischen Wochenschrift enthaltenen spasshaften Druckfehler zu berichtigen. Es heisst im Original : »die farblosen Blutkörperchen kriechen wie Amoeben zwischen den rothen umber «; dem Setzer erschien es drastischer zu sagen: wie Ameiseu! Und das hat Anklang gefunden, denn mir sind meine Blutkörperchen noch einmal anderswo sechsbeinig begegnet.

1) Joh. Müller's Archiv etc. 1854 , p. 14.

2) M. Schultze, das Protoplasina der Rhizopoclen und der Pflanzenzellen. 1863. p. 46. W. Kühne, Untersuchungen über das Protoplasma. 1864. p. $100 \mathrm{ff}$. Jul. Sachs, Flora 1864, No.3, p. 39, $49 \mathrm{ff}$. 
gen. In einem unter Deckgläschen zu einer dünnen Schicht ausgebreiteten Tropfen frischen Blutes stellen sich, wenn die Temperatur des heizbaren Objecttisches auf $36-40^{\circ} \mathrm{C}$. erhalten wird, so lebhafte Bewegungen der meisten farblosen Blutkörperchen ein, dass neben ihnen die bisher allein bekannte langsame Formänderung, welche dieselben Körperchen bei gewöhnlicher Zimmertemperatur zeigen, als ein Zustand fast vollkommener Ruhe erscheint. Es sind Veränderungen, welche den tliessenden Bewegungen der kleinen Amoeben, die gewöhnlich als Amoeba diffluens bestimmt werden, an Lebhaftigkeit wenig nachgeben. Nicht nır, dass die Gestaltveränderungen sehr viel schneller ablaufen, als bei gewöhnlicher Zimmertemperatur, auch der Character der Bewegung ist ein anderer. Während wir es bei $15-20^{\circ} \mathrm{C}$. für gewöhnlich nur mit einem äusserst langsamen, so zu sagen planlosen Ausstrecken und Einziehen von Fortsätzen zu thun haben, beobachtet man jetzt Veränderungen, welche auf eine Ortsbewegung hinzielen. Das farblose Blutkörperchen schmiegt sich der Glasoberfläche dicht an und sendet ein oder mehrere wie tastend sich vorschiebende Fortsätze aus, denen nachfliessend die ganze Masse kriechend folgt. Oder der vorgeschobene Theil verdient eigentlich nicht den Namen eines "Fortsatzes", es ist vielmehr ein breit vorrückender Vordertheil des Körperchens, welcher die andere hintere Hälfte nachschleppt. Kurz gesagt, die firblosen Blutkörperchen kriechen zwischen den rothen wie Amoeben umher, bald frei an der Oberfläche des Glases sich hinschmiegend, bald in einen Haufen rother Körperchen eintretend und die einzelnen auseinanderdrängend, um da oder dort sich einen Weg zu bahnen. Das im abgekühlten Blute glänzende, stark lichtbrechende und von ziemlich scharfem Contour begränzte kuglige oder nahezu kuglige Körperchen breitet sich während des Kriechens zu einer dünnen, stellenweise von den zartesten Contouren begränzten, vielgestaltigen Platte aus, welche hierhin und dorthin Fortsätze vorschiebt, die sich oft zu längeren Fäden ausziehen, um dann mit der ganzen Masse nachzurücken. Die feinkörnige Substanz des Körperchens, das Protoplasma, ist dabei in fortwährender, mit den Formveränderungen Hand in Hand gehender Bewegung, und wo, wie bei vielen farblosen Blutkörperchen, die Granula des Inneren stark lichtbrechend und einzeln leicht wahrzunehmen sind, bieten diese in ihrer wie Hiessenden Bewegung auch schon bei mässig starker, circa 400maliger Vergrösserung ein deutliches Bild der inneren Veränderungen im Protoplasma. Auch die Kerne, 
ein einfacher oder mehrfache, wie sie den meisten der farblosen Blutkörperchen zukommen, sind bei diesen Bewegungen manchmal zu verfolgen. Meist zeichnen sic sich bei gleicher Lichtbrechung wie das Protoplasma von diesem wenig scharf ab. Mit sehr guten und stark vergrössernden Linsen (Zeis F, Hartnack 9 und 10) erkennt man jedoch den Kern oftmals, wenm auch nur undeutlich begränzt, namentlich in den dunkel granulirten Körperchen, wo er sich als heller Fleck zu erkennen giebt, und hier kann man seine von den Formveränderungen abhängigen Wanderungen von einem Ende der Zelle zum anderen beobachten. Wie fest die Körperchen während des Kriechens an der Glaswand haften, geht aus dem Widerstande hervor, den sie den Strömungen des Plasma, durch welche die rothen Körperchen fortgeführt werten, entgegensetzen. Bei der Beobachtung auf dem warmen Objecttisch entstehen oft plötzlich sehr lebhafte Strömungen in dem Präparate, wahrscheinlich bedingt durch eine da oder dort am Rande des Deckgläschens lebhafter vor sich gehende Verdunstung. Bei solchen, das ganze Gesichtsfeld in die grösste Aufregung versetzenden Bewegungen sah ich die kriechenden Körperchen stets ihren Platz behaupten.

Aber wie bekannt sind nicht alle farblosen Blutkörperchen von gleicher Art und auch in dem Modus der Bewegungen kommen Verschiedenheiten vor. Die Unterschiele, welche auch dem flutchtigen Beobachter des Blutes nicht entgehen können, betreffen die Grösse. Dieselbe variirt ziemlich bedeutend. Vielfach besprochen ist ferner das Verhalten der Kerne, die bald gross und einfach, bald kleiner und zahlreich in einem farblosen Blutkörperchen angetroffen werden. Endlich findet man, wie schon Wharton Jones ${ }^{1}$ ) hervorhebt, im Blute des Menschen wie der meisten Thiere fein und grob granulirte farblose Körperchen nebeneinander, ein Unterschied, dessen die späteren Beobachter meist nur sehr obenhin Erwähnung thun ${ }^{2}$ ).

Ich unterscheide in meinem und dem Blute einiger anderer Personen folgende Arten farbloser Körperchen oder Zellen (vergl. Fig. 3-9 Taf. II. Vergröss. 700). Ich beginne mit den kleinsten Formen (Fig. 3), deren Grösse die der rothen Blutkörperchen nicht er-

1) Philosophical transactions $1846, I$, p. 82.

2) Für das Blut des Frosches hat Rindfleisch das Verdienst, auf das constante Vorkommen dieser Modification der farblosen Zellen, die er Körnchenzellen nennt, nachlrücklichst aufmerksam gemacht zu habę (Experimentalstudien über d. Histologie des Blutes. Leipzig 1863). 
reicht, oft sogar ansehnlich geringer bleibt, wie eine Vergleichung mit den bei gleicher Vergrösserung in Fig. 1 abgebildeten rothen Blutscheibchen zeigt. Es sind kuglige Zellen mit sehr zarter äusserer Begrenzung, wenig körnig und in ihrem Lichtbrechungsvermögen nicht viel verschieden von der umgebenden Flüssigkeit. Schon ohne Zusatz von Reagentien unterscheidet man an ihnen einen grossen kugligen Kern, umgeben von einer sehr geringen Menge von Protoplasma. Die kleinsten dieser Körperchen, welche in meinem Blute vorkommen, und einen Durchmesser von $0,005 \mathrm{Mm}$. besitzen, gleichen an Grösse fast genau den Kernen der etwas grösseren, bei welchen letzteren eine dünne Rinde von Protoplasma auf der Oberfläche des Kernes unzweifelhaft vorhanden ist. Dass die kleinsten Formen des Protoplasma im Umkreise des Kernes ganz entbehren, möchte ich nicht behaupten, doch wird man ihnen nur eine verschwindend geringe Menge dieser Substanz zuschreiben können. In den grösseren dieser Körperchen habe ich öfter ohne Zusatz von Reagentien zwei nebeneinanderliegende und mit ahgeplatteten Flächen einander berüihrende, also planconvexe Kerne und in jedem derselben ein deutliches Kernkörperchen gesehen. Das l'rotoplasma ist aber auch bei diesen, wie die Figur 3 lehrt, nur als dünne Rinde um den einfachen oder doppelten Kern vorhanden. Ueber die feinere Structur des Protoplasma lässt sich bei der sehr geringen Menge desselben nichts Genaneres aussagen. Einzelne erkennbare Körnchen fehlen meist, es ist nur eine leichte Trübung, welche eine Andeutung von körniger Beschaffenheit giebt. Diese die Grösse der farbigen Blutkörperchen nicht erreichenden farblosen Elemente zeigen auf dem warmen Objecttisch bei Körperwärme $\left(38-40^{\circ}\right.$ C. $)$ keine Bewegungen oder Gestaltveränderungen.

Diesen Formen reihen sich unmittelbar etwas grössere an, welche den Durchmesser der gewöhnlichen farbigen Körperchen besitzen oder noch etwas unter demselben bleiben. Ihr Protoplasma ist in ansehnlicherer Menge vorhanden, bei meist unverändertem Caliber des Kernes (Fig. 4). An diesen Körperchen stellen sich bei Körperwärme Formveränderungen ein, sie treiben kurze," meist zugespitzte Fortsätze und ziehen dieselben wieder ein. Zu eigentlich kriechenden Bewegungen sah ich sie nicht kommen. Ihr Protoplasma ist äusserst fein granulirt, von Molekularbewegung ist in demselben Nichts zu sehen.

Erst an dritter Stelle gelingen wir zu denjenigen farblosen 
Blutkörperchen, welche man clen bisherigen Beschreibungen gemäss als die typische Form bezeichnen kann. Sie stellen in ruhenden Zustande Kugeln dar von 0,009-0,012 Mm., also einem Durchmesser, welcher den eines farbigen Körperchens etwas, höchstens um die Hälfte übertrifft (Fig. 5a). Im frisch aus der Ader gelassenen Blute trifft man sie selten kuglig, es sind meist, wie in Fig. áb gezeichnet, unregelmässig verzogene Formen. Die Granulationen des Protoplasma sind ausserordentlich fein, von Molekularbewegung ist an ihnen Nichts wahrzunehmen. Kerne sieht man nur ausnahmsweise blass durchschimmern, ein oder zwei, auch wohl mehr, deren Grösse, wenn sie in einfacher Zahl vorhanden sind, derjenigen des Kernes der kleineren Körperchen gleich ist, mit der Vermehrung der Kerne aber abnimmt. Höchst überraschend ist das Schauspiel, welches diese Körperchen bei Körpertemperatur auf dem warmen Objecttisch darbieten. Sobald bei langsamem Heizen die Temperatur des Bluttropfens auf dem warmen Objecttisch $35^{\circ} \mathrm{C}$. erreicht hat und bis 38 oder $40^{n}$, auch etwas darüber, ansteigt, beginnen sie Bewegungen auszuführen, welche denen einer kriechenden Amoebe gleichen (vergl. Fig. 8). Das vorher kugelige, etwas glänzende, weil ziemlich stark lichtbrechende Körperchen breitet sich an der Oberflüche des Glases in die Fläche aus und erhält dadurch zunächst blissere Contouren. Aber die Ausbreitung findet nicht nach allen Richtungen hin gleichmässig statt. Es ist als wenn das Körperchen nach einer Richtung hin zerfliessen wollte, und nach dieser schiebt sich eine äusserst blasse, feinz a ckig be gränzt e Masse vor, während sich der stärker lichtbrechende, noch glänzende Theil langsam nachschiebt. Oder die Ausbreitung findet nach mehreren Richtungen zugleich statt und wird hier, wenn auch mit feinzackigem, wie auf der Oberfläche des Glases klebendem Rande vorrückend, langgestreckt fadenförmig, dort breit plattenförmig. Die Bewegung nach einem dieser Fortsätze gewinnt dann die Oberhand und das Körperchen kriecht jetzt, durch keinerlei Strömungen in der Blutflüssigkeit gestört, zwischen den ruhenden oder strömenden farbigen Blutkörperchen hin, weicht hier aus, zwängt sich dort durch eine Enge und nimmt in schneller Folge alle denkbar verschiedenen Gestalten an.

Ist an den ruhenden kugligen Körperchen über die feinere Structur des Protoplasma wenig auszumitteln, so bieten die flächenhaft ausgebreiteten, kriechenden Formen eine etwas befriedigendere Einsicht. Man unterscheidet mit den stärksten Vergrösserungen an 
den vorrückenden, feinzackig begränzten Fortsätzen einen fast hyalinen Rand, eine äusserst blasse, körniger Structur, wie es scheint entbehrende Rindenschicht und in dem blasskörnigen Innern zwei offenbar verschiedene Arten von Körnchen, glänzende, wie es scheint etwas stärker lichtbrechende als die Grundsubstanz, doch nur ausnahmsweise so gross, dass man sie ringförmig begrïnzt, also messbar gross nemnen könnte, und eine andere Art, welche ich für schwächer lichtbrechend als die Grundsubstanz halte, kleinere und grössere runde Bläschen, welche den Eindruck wie V a cuol en machen, welche wie Lücken in der Substanz aussehen, d. h. weder beim Heben noch Senken des Tubus glänzen. Diese kleinsten Vacuolen, denn als solche will ich sie schlechtweg bezeichnen, sind offenbar zum guten Theil Ursache des feingranulirten Ansehns der in Rede stehenden Blutkörperchen. Dass neben ihnen jedoch wirkliche Körnchen vorkommen, ist unzweifelhaft, und geht unter Anderem aus den Veründerungen hervor, welche Wasserzusatz an diesen Blutkörperchen hervorruft. Unter den Erscheinungen geringen Anschwellens verwandeln sie sich bekanntlich in helle Kugeln, in deren Innerem eine lebhafte Mol ekularbew egung kleinster Körnchen auftritt. Von einer solchen ist an den kriechenden Blutkörperchen Nichts zu sehen; die Consistenz des lebendigen Protoplasma schejnt dieselbe nicht zu Stande kommen zu lassen.

Wenn ich eine dünne hyaline Rinde und ein körniges Innere an diesen Körperchen zu unterscheiden meine, so bin ich doch weit entfernt, eine scharfe Grenze beiderlei Substanzen anzunehmen. Eine solche dürfte sicher nicht vorhanden sein, wie denn überhaupt jeder Anschein einer Me mbran auf der Oberfläche dieser farblosen Blutkörperchen fehIt. Was die Kerne derselben betrifft, so sollte man meinen, müssten solche bei der Abplattung des Körpers während des Krieehens deutlicher zu erkennen sein. Dem ist jedoch in vielen Fällen nicht so. Wenn es mir auch wiederholt gelungen ist, einen, zwei oder drei Kerne im Innern wahrzunehmen, so waren die Grenzcontouren derselben doch immer sehr blass und manchmal gerade zu zweifelhaft; in anderen Fällen aber fehlte jede Andeutung eines Kernes. Es wäre aber sicher voreilig, daraus auf die Abwesenheit solcher Kerne zu schliessen. Wir wissen schon, dass dieselben sich in der Art ihrer Lichtbrechung kaum von dem Protoplasma lebender Zellen unterscheiden, und je dicker die den Kern umgebende Schicht des Protoplasma ist, un so schwerer hält es ersteren wahr- 
zunehmen. Nun kommt es aber bei den kriechenden Blutkörperchen oft genug vor, dass neben den fast hyalinen, blassen, kriechenden, ausgebreiteten Fortsätzen ein dickerer, glänzender 'Theil des Zellenkörpers vorhanden ist, in welchem der Kern sich dem Beobachter entziehen kann. Und Verdümnung des Blutes mit schwacher Essigsäure lässt bekamntlich keinen Zweifel, dass wenigstens der bei weitem grösste Theil der furblosen Körperchen sicherlich mit einem oder mehreren Kernen auscerüstet ist.

Haben wir hiermit eine Darstellung des Verhaltens der gewöhnlichsten Form der farblosen Blutzellen gegeben, so bliebe uns nun noch die Besprechung einer nicht seltenen Modifikation derselben übrig, welche ich im Anschluss an Wharton Jones die grob granulirte Form gegenüber der vorigen Art, der feingranulirten, nennen will. $\mathrm{Zu}$ allen 'Tageszeiten, wenn auch bezïglich ihrer Menge gleich den übrigen furblosen Blutzellen sehr variirend, finde ich in meinem und dem Blute anderer Personen spärlich farblose Zellen, welche sich durch eine mehr oder minder grosse, meist recht ansehnliche Menge kleiner, stark lichtbrechender, deutlich kugliger Körner auszeichnen, welche etwa den Glanz kleinster Fettkörnchen haben (vergl. Fig. 6 und 9). In (ler Ruhe von kugliger Form gleichen sie an Grösse den feingranulirten, d. h. übertreffen meistens die der rothen um ein Weniges. Lassen sich die dunkeln Kïornchen schon in dem Ruhezustand der Zellen oft deutlich einzeln wahrnehmen, wobei $z$ bemerken, dass eine Molekularbewegung an ihnen nicht zu beobachten ist, so treten dieselben doch schärfer einzeln hervor, wenn die Körperchen bei einer Temperatur von etwa $38^{n} \mathrm{C}$. ihre kriechenden Bewegungen ausführen. Schon bei Zimmertemperatur beobachtet man an ihnen wie an den feingranulirten die von Li eberkühn beschriebenen Bewegungen, d. h. eine Formveränderung beruhend auf einem langsamen Ausstrecken und Einziehen von Fortsätzen (Fig. 6 b.). Steigert man die Temperatur auf Körperwärme, so erfolgen die Bewegungen ungleich rascher, die Gestaltveränderungen werden viel auffallender (Fig. 9), und es tritt ein schneller auf der amoebenartig kriechenden Bewegung beruhender Ortwechsel auf in durchaus analoger Weise, wie wir ihn eben bei den feingranulirten Körperchen beschrieben haben. Nicht nur für die Bewegungen im Ganzen sondern namentlich auch für die inneren des Protoplasma bieten diese grobgranulirten Kürperchen ein viel bequemeres Bild als die feingranulirten, denn wenn auch die stärksten und besten Linsen zur Verwendung 
kommen (Zeis F, Hartnack 10), so bleibt immer die Beobachtung der feingranulirten Körperchen auf dem warmen Objecttisch eine Aufgabe, zu deren einigermaassen befriedigenden Lösung es jedenfalls einer sehr günstigen Beleuchtung und einiger Austrengung der Augen bedarf. Einen sofort auffallenden Vortheil gewährt die Beobachtung der grobgranulirten Körperchen dadurch, dass während der Veränderungen in ihrer Gestalt zugleich die innere Bewegung der Körnchen deutlich verfolgt werden kamn. Das langsame Fliessen derselben, oder das plötzliche Nachstürzen bei schnell hervorgetriebenem breiten Fortsatz gewährt ein leichter übersichtliches Bild der Bewegungen, welche das Protoplasma dieser Zellen ausführt. Namentlich in den lang ausgezogenen Fäden, welche an einigen der in Fig. 9 abgebildeten kriechenden Körperchen clargestellt sind, ist die gleichmässig fliessende Bewegung der Körner sehr auffallend, um so mehr als bei der äussersten Durchsichtigkeit und geringen Granulation der Protoplasmasubstanz oft nur die Körnchenreile gesehen wird, zumal wenn das Körperchen sich zwischen vielen rothen hindurchdrängt, also nicht frei in der Bluttlüssigkeit bewegt. Die Bewegmg der Körnchen in einem solchen langen Fortsatz ist übrigens keine hin- und rückfflessende, wie ich hier ausdrücklich im Vergleich mit der der Rhizopoden-Pseudopodien hervorhebe, sondern nur nach einer Richtung verlaufende, entsprechend derjenigen, nach welcher dis Protoplasma selbst sich bewegt. Bezüglich der Art der Bewegung und der. Gestalt der Fortsätze besteht noch ein gewisser Unterschied gegenüber den feingranulirten Körperchen. Während bei letzteren die Verbreiterung der Substanz, einem Zerfliessen ähnlich sieht, indem die feinzackige Begrenzung der zu verschwindender Dünne ausgebreiteten Masse zeitweise den Gedanken aufkommen lässt, dass hier überhaupt eine scharfe Begrenzung zu existiren aufgehört habe, zeigt sich bei den kriechenden Bewegungen der grobgranulirten Körperchen ein schärferer und mehr abgerundeter Grenzcontour. Das Protoplasma stellt hier allem Anschein nach eine etwas consistentere, wenigstens an der Obertäche resistentere Substanz dar, während die Bewegungsfähigkeit dieselbe wie bei den feingranulirten ist, indeın die Gestaltveränderungen im Allgemeinen ebenso schnell ablaufen und innerhalb derselben Extreme schwanken wie dort.

Wie Fig. 9 zeigt, sind an den grobgranulirten Körperchen die Zellenkerne meist deutlich wahrzunehmen, freilich nicht immer scharf begrenzt, so wenig wie bei den feingranulirten, vielmehr durch Ver- 
drängung der Körner nur helle Flecke in der grobgranulirten Zellsubstanz erzengend. Ihre Zahl beträgt 1 oder 2, ihre Lage variirt. Sind zwei Kerne vorhanden, so können dieselben dicht beisammen oder an entgegengesetzten Enden der Zelle liegen.

Wenn ich, wie Whart on Jon es, fein- und grobgranulirte Körperchen im Blute des Menschen unterscheide, so muss ich doch gleich hinzufügen, dass Uebergänge zwischen Beiden vorkommen. Aber die Uebergangsformen werden seltener angetroffen als die Extreme, und die Unterscheidung lässt sich daher jedenfalls rechtfertigen. Uebergangsformen aber wird man solche Körperchen zu nemmen haben, die bei dem Ansehm und Benehmen der feingranulirten einige stärker lichtbrechende Körnchen, nach Art derjenigen der grobgranulirten, enthalten. Einige solche Körperchen zeigt Fig. 7. Sie kommen in verschiedenen Grössen vor.

Nach Beobachtung der ganz unerwartet lebhaften, kriechenden Bewegungen, welche die farblosen Blutkörperchen des Menschenblutes bei Körperwärme ausführen, und bei ihrer durch Obiges hinreichend constatirten Aehnlichkeit mit gewissen zartesten Amoebenformen musste sich sofort die Frage aufdrängen, ob sich an ihnen eine A u f n a hme fester Körper in das Protoplasin a nach Art einer fressenden Amoebe werde beobachten lassen. Eine bejahende Antwort musste um so wahrscheinlicher in Aussicht stehen, als die Möglichkeit einer Aufnahine von Farbstoffpartikelchen, welche dem Blute künstlich beigemischt worden waren, in das Protoplasma der farblosen Blutzellen und Lymphkörperchen bei kaltblütigen Thieren bereits wiederholt constatirt worden war. Nach den ersten entscheidenden Beobachtungen, welche-von $\mathrm{E}$. Haeckel herrühren, welcher bei Gelegenheit seines für die Naturgeschichte der Rhizopoden so denkwürdigen Aufenthaltes am Mittelmeere eine Reihe von Experimenten an Mollusken und Krebsen ausführte und den Uebergang von Farbstoffmolekeln in die Blutkörperchen innerhalb und ausserhalb des Blutstromes auf das Schlagendste nachzuweisen vermochte ${ }^{1}$ ), gelang es v. Recklinghásen ${ }^{2}$ ), an den Lymph- und farblosen Blutkörperchen des Frosches innerhalb, und später Preyer ${ }^{3}$ ) an den farblosen Blutkörperchen desselben Thieres ausserhalb des Körpers die

1) Die Radiolarien, Berlin 1862, p. 104.

2) Die Lymphgefässe und ihre Beziehung zum Bindegewebe. Berlin 1862 , p. 22.

3) Virchow's Archiv Bd. XXX, p, 420.

I Schultae, Irchir f. mihrosk. Inatome. I. lid. 
Aufnahme von Milchkügelchen und Farbstoffmolekeln in das Innere der genannten Körperchen zu beobachten. Bei den trägen Bewegungen, welche diese Zellen ausserhalb des Körpers auf dem Objectträger ausführen, konnte es nur der grössten Ausdauer gelingen, die Aufnahme des Farbstoffes in das Innere direct $z u$ beabachten. Weit günstiger in dieser Beziehung mussten die schnell kriechenden Körperchen des auf $30-40^{\circ} \mathrm{C}$. erwärmten Menschenblutes erscheinen, und die Voraussetzung wurde durçh die Beobachtung bestätigt.

Ich mischte zunächst eine Spur fein vertheilten Carmins mit einem Tropfen frischen, aus dem Finger entnommenen Blutes auf dem Objectträger und beobachtete bei $38^{n} \mathrm{C}$. Schon nach wenigen Minuten sah ich die meisten der kriechenden Zellen vereinzelte Carminkörnchen- mit sich herumtragen. Ich sah solche Farbstoffpartikelchen mit den Elementarkörnchen des Protoplasma von einem Fortsatz der Zelle in den andern wạndern, sah wie sie in lang ausgezogenen Fäden des Protoplasma nachgeschleppt und mit diesen wieder eingezogen wurden. Sie lagen bald in grösseren Klümpchen beisammen bald vertheilten sie sich in die Fortsätze, je nach der Gestalt und den inneren Bewegungen der Zelle, so dass auch nicht der geringste Zweifel übrig blieb, dass der Carmin wirklich in das Protoplasma aufgenommen war und nicht etwa blos der klebrigen Oberfläche der Blutkörperchen anhaftete. Um die kriechenden Zellen möglichst frei, ungehindert durch herumliegende rothe Blutkörperchen beobachten zu können, verdünnte ich das Blut mit Jodserum, einem durch Zusaltz von Jodtinctur oder Jod in Substanz vor Fäulniss bewahrten Amnioswasser jüngerer Wiederkäuer-Embryone. Ich habe diese Flüssigkeit in Virchow's Archiv Bd. XXX, p. 263 beschrieben und als Zusatzflüssigkeit bei Untersuchung frischer Gewebe empfohlen und kann sie, je länger ich dieselbe benutze, nur um so mehr rühmen. Enthält sie nicht zu viel Jod, so dass die Farbe nicht dunkler als die des Urines ist, so stört sie die Bewegungen der farblosen Blutkörperchen in keiner Weise, und erleichtert, indem sie das Blut verdünnt, die Beobachțung einzelner Elemente sehr. Bei Anwẹndung dieser Flüssigkeit zur Verdünnung des Blutes ist nur zu berücksichtigen, dass sie einen Concentrationsgrad besitzt, welcher die rothen Blutkörperchen nicht zackig macht. Tritt eine solche Veränderung bei der grösseren Zahl der Blutkörperchen ein, so verdünnt man das Jodserum mit ein wenig Wasser. In dieser Flüssigkeit erhält sich die Bewegung der farblosen Blutkörperchen bei Körperwärme ebenso 
lange, und das Aufnehmon von Carminkörnchen, die man in foinvertheiltem Zustande dem Jodserum vorher beimischte, tritt ebenso schnell ein wie im unverdünnten Blute. Immerhin ist auch das Jodserum eine fremkartige Beimischung, die man als möglicher Weise schädlich mit grosser Vorsicht anzuwenden hat. In der That sind in einem auf das dünnste ausgebreiteten Bluttropfen die Blutkörperchen so gut einzeln zu beobachten, und durch hinreichende Zwischenräume von einander getrennt, dass die Verdünnung des Blutes zur Beobachtung der Bewegung der farblosen Körperchen nicht absolut nothwendig ist. Un das Blut aber in dünnster Schicht unter dem Deckgläschen auszubreiten, bediente ich mich vielfach der vòn $R$ ind fl eisch empfohlenen Methode ${ }^{1}$ ), welche darin besteht, das Deckglüschen unter Beobachtung gewisser Cautelen trocken auf den Objecttrigrer mittelst einiger Wachströpfchen aufzukitten, und das Blut nachträglich in den capillaren Raum von der Seite her eintreten zu lassen. Es liegt auf der Hand, dass unter Umständen diese Methode einige Vortheile vor der gewöhnlichen zu bieten vermag, z. B. um das Eintreten grösserer Farbstoffklümpchen unter das Deckglïschen zu vermeiden. $\mathrm{Zu}$ dem Zwecke aber, eine möglichst dünne Schicht von Blut zur Beobachtung zu erlangen, ist das umständlichere Verfahren nicht nothwendig, vielleicht sogar mit entschiedenen Nachtheilen verbunden. Ist rer capillare Raum, wie beabsichtigt wird, von der ïussersten Dünne, so vermag sich in demselben ein rothes Blutscheibchen nicht auf die Kante zu stellen. In einen solchen werden die kugligen forblosen Körperchen nicht oder nur zum Theil eintreten. Auch die klebrige Beschaffenheit der Oberfläche dèr letzteren hindert ihr gleichmässiges Vorrücken in dem engen Raume. Ich überzeugte mich öfter, dass ein auf die $R$ indfl eisch'sche Methode bereitetes Blutpräparat weniger farblose Körperchen enthielt, als ein auf die gewöhnliche Weise gefertigtes. Um eine möglichst dünne Schicht von Blut zu erhalten drücke ich das auf den Bluttropfen gelegte Deckglas mit einer Nadel mässig fest auf, und sauge dann mit einem feinen Tuche oder mit Fliesspapier das über den Rand tretende Blut ab. So erhalte ich, vorausgesetzt dass:Objectträger und Deckglas ganz ebene, geschliffene Flächen haben, untackelhafte Präparate.

Statt des Carmins wandte ich mit gleichem und zum Theil noch besserem Erfolge einige andere Farbstoffe an, nämlich Zinober, In-

1) Experimentalstudien über die Histologie des Blutes. Leipzig 1863, p. 21. Virchow's Archiv Bd. XXX, p. 603. 
digo und Anilinblau, endlich auch Milch. Die Körnchen des Zinober sind meist feiner als die des Carmins, die Aufnahme erfolgt sehr schnell und in ziemlich grosser Menge, so dass die Bewegungen der Farbstoffkörnchen im Protoplasma während des Kriechens der Zellen meist an vielen Objecten desselben Präparates mit der grössten Deutlichkeit beobachtet werden konnten (Fig. 10). Das Anilinblau hat in den feinsten Körnchen eine intensivere und weit schönere Farbe als der Indigo, lässt sich auch sehr gut im Blut fein vertheilen und verdient daher, da eine Aufnahme in die Zellen ebenso leicht stattfindet wie beim Indigo, alle Berücksichtigung.

Wie sich in der Art der Fortbewegung und der Gestalt der kriechend vorgeschobenen Rindenpartien Unterschiede zwischen den fein- und grobgranuiirten Körperchen zeigten, so haben wir solche auch den Farbstoffen gegenüber zu constatiren. Im Allgemeinen sind die grobgranulirten viel weniger geneigt zur Aufnahme fremder Körper als die feingranulirten, was offenbar mit der Verschiedenheit in der Consistenz der Rindenschicht des Protoplasma zusammenhängt, wie wir sie anzunehmen uns berechtigt hielten. Es kommt aber eine Aufnahme von Farbstoffen auch bei den grobgranulirten Körperchen vor, wie ich unter anderen bei Versuchen mit Anilinblau beobachtete. Ein solches mit einigen blauen Körnchen im Innern versehenes Körperchen ist in zwei verschiedenen Gestalten in Fig. 12 abgebildet. Auffallend war es mir aber, dass die Lebhaftigkeit der Bewegung durch die Aufnahme des Farbstoffes offenbar sehr abgenommen hatte, eine Erscheinung, die mir übrigens auch oft an den feingranulirten Körperchen begegnet ist.

Der Moment, in welchem die Farbstoffmolekeln in das Innere des Protoplasma aufgenommen werden, ist, wie es scheint, durch kein besonders auffallendes Manöver bezeichnet. Besondere Fortsätze, welche die Zelle zur Bewältigung des fremden Körpers ausstrecke, habe ich nie gesehen. Was ich beobachten konnte beschränkte sich darauf, dass während des gleichmässig fortschreitenden Kriechens der Farbstoff wie durch Druck in das Innere des Protoplasma hineingepresst wird. Es könnte vermuthet werden, dass zu dieser Aufnahme fremder Körper eine Stelle der Oberfläche anderen gegenüber besonders geeignet sei. Die Vermuthung hat jedoch an sich wenig Wahrscheinlichkeit für sich, und wird durch die Beobachtung nicht gestützt, da nach den Erscheinungen, welche die kriechenden Körperchen darbieten, die Beschaffenheit ihrer Oberfläche ringsum eine gleiche 
zu sein scheint. Noch wäre zu erwähnen, dass gewöhnlich beim Mischen des frischen Bluttropfens mit dem fein pulverisirten Farbstoff sofort ein gewisser Theil des letzteren der bekanntermaassen schleimigklebrigen Oberfläche der farblosen Blutkörperchen anhaftet, welcher dann bei den ersten kriechenden Bewegungen auf dem geheizten Objecttisch sofort theilweise oder ganz in das Innere aufgenommen wird, so dass in diesem Falle der Moment des "Fressens" in seinen einzelnen Stadien nicht zur Beobachtung gelangt.

Von besonderem Interesse sind die Versuche mit $\mathrm{Milch}$, insofern die Grösse der aufgenommenen Milchkügelchen die der Farbstoffmolekel bei weitem übertrifft. Bei einer Verdünnung des Blutes mit etwa zwei Drittel des Volumen frischer Kuhmilch, wie ich sie ausführte, verändern sich die geformten Elemente dles Blutes in keiner merkbaren Weise, und, auf den geheizten Objecttisch gebracht, kriechen die farblosen Blutkörperchen mit derselben Schnelligkeit, halten sich auch bei der Körpertemperatur fast ebenso lange lebendig, wie im unverdünnten Blute. Sofort nachdem die kriechenden Bewegungen sich eingestellt haben. beobachtet man Blutkörperchen, denen kleinere und grössere Milchkügelchen anhaften. Die kleinen und die mittelgrossen unter ihnen, ilarunter solche von 0,003 Mm. Durchmesser. gelangen schnell in das Innere des Protoplasma und werden in diesem mit den ihm eigenthümlichen Körnchen hin- und hergetrieben. Ich habe in Fig. 13 ein Blutkörperchen abgebildet, welches fünf verschieden grosse Milchkügelchen enthielt. Als ich dessen zuerst ansichtig wurde, waren die letzteren in ein Klümpchen geballt in einem Fortsatz eingeschlossen, der dem Körper der Zelle beim Kriechen nachgeschleppt wurde. Dieser Fortsatz wurde sodann eingezogen und die Milchkügelchen geriethen so in die Nähe der Mitte der Zelle, in. welcher sie ihre gegenseitige Lage bald veränderten, indem einige derselben beim Kriechen der Zelle dem fliessenden Protoplasma folgend nach vorn vorrückten.

Musste uns schon die Beobachtung der kriechenden farblosen Blutzellen, wie sie sich in den verschiedenen Stadien der Bewegung präsentiren, zu der Ueberzeugung bringen, dass ihnen eine vom Protoplasma verschiedene Hülle, eine Zellm embran im Sinne der alten Schule, nicht wohl zugesprochen werden könne, so tragen natürlich die gelungenen Versuche der Fütterung mit Farbstoffen und Milchkügelchen nur zur Befestigung dieser Ansicht bei. Die Beobachtung der kriechenden Formen zeigt keine Andeutung einer Membran, die 
physikalischen Eigenschaften ihrer Obertläche sprechen vielmehr auf das Entschiedenste für ein nacktes Protoplasma, die dem Anschein nach an jeder Stelle der Oberfläche mögliche Aufnahme fremder Körper in das Innere wäre bei Existenz einer Membran, wenn wir derselben nicht mindestens e in e grössere Oeffnung zuschreiben wollen, von der absolut Nichts zu sehen ist und gegen die jede Analogie spricht, ein Paradoxon. Unter diesen Umständen kann es für mich keinen Augenblick zweifelhaft sein, dass ich die farblosen Blutzellen des Menschen den membranlosen Zellen zurechne, denjenigen Zellen, welche nach meinen an verschiedenen Orten niedergelegten Beobachtungen nur aus Protoplasma mit eingeschlossenem Kern bestehen und entgegen den früher herrschenden Ansichten eine grosse Verbreitung in den Geweben auch des erwachsenen Thierkörpers finden: Sie schliessen sich in dieser Beziehung unmittelbar an die Blutzellen der wIrbellosen Thiere an, für welche E. H a e c k e 1 bereits aussprach, dass sie "hiüllen los e Protoplasmaklumpen( darstellen ${ }^{1}$ ). E. Ha eckel hat schon die Vermuthung geäussert, dass ein wesentlicher Unterschied in der fraglichen Beziehung zwischen den Blutzellen der Wirbellosen und den farblosen Elementen des Blutes dér Wirbelthiere, welche Gebilde ja auch früher iǹmer mit einander verglichen worden sind, nicht existire. Die Beobachtungen mittelst des heizbaren Objecttisches habeı die Möglichkeit an die Hand gegeben, jeden Zweifel zu lösen. Uebrigens haben sich bezüglich der farblosen Blutzellen und Lymphkörperchen des Frosches bereits v. Reckl inghausen ${ }^{2}$ ) und W. Preyer ${ }^{3}$ ) in ganz gleichem Sinne ausgesprochen.

Ich habe weiter bezüglich der Lebensthätigkeiten der farblosen Blutkörperchen noch nach zwei Richtungen hin einige Versuche angestellt, über welche ich hier berichten will. Ich suchte zu ermitteln, wie lange nach der Entfernung aus dem Körper die genannten Elemente lebendig bleiben $d . h$. ihre Contractilität bewahren können, und wie hoch die Temperatur des Blutes steigen könne, ohne dass sie ihr Leben einbüssen. Ich bediente mich bei diesen Versuchen nur des Menschenblutes. Die Lebensdauer der farblosen Blutkörperchen zeigte sich, wie sich voraussetzen liess, in hohem Grade abhängig von der Temperatur, bei welcher man das Blut aufbewahrt. Ein Tropfen frischen Blutes unter Deckgläschen in der feuchten

1) Die Radiolarien, p. 104.

2) Virchow's Archiv Bd. XVIII, p. 184.

3) Virchow's Archiv Bd. XXX, p. 420. 
Kanmer bei $38-42^{n} \mathrm{C}$. der Beobachtung unterworfen, bietet bei dieser 'Temperatur nach Verlauf von 2-3 Stunden keine Bewegungen der farblosen Blutkörperchen mehr dar, und kömnen solche auch durch niedere oder höhere Temperaturgrade nicht wieder hervorgerufen werden. Das Aussehen der Zellen ist verändert, es fellt die bestimmte äussere Begrenzung, man meint sie seien zerflossen. Dic Zahl und Grösse der hellen, blassen Räume in ihrem Innern, welche man Vacuolen nennen kann, hat zugenommen, sie sind offenbar abgestorben und in beginnender Zersetzung begriffen. An einem ebensolchen zwischen 36 und $38^{\circ} \mathrm{C}$. aufbewahrten Blutpräparate komnten noch nach drei Stunden an einigen wenigen farblosen Blutkörperchen Bewegungen wahrgenommen werlen, welche aber nach kurzer Zeit aufhörten. Dagegren erhielten sich die Blutkörperchen eines vor Verdunstung geschützten, unter Deckglas aufgestellten Bluttropfens, wenn derselbe gleich nach der Entleerung in eine Temperatur von $3-5^{0} \mathrm{C}$. gebracht wurde, viele Stunden lebensfahig, wie die bei der Erwärmung eintretenden lebhaften kriechenden Bewegungen derselben bewiesen. Solche beobachtete ich noch nach 20 Stunden, während in mehreren 24 und 36 Stunden aufbewahrten Blutproben die farblosen Körperchen abgestorben waren. Viel günstiger für die Erhultung des Lebens gestalten sich die Verhältnisse, wenn man das Blut nicht in einem einzelnen Tropfen unter Deckglas, sondern in grösseren Quantitïten in Gläsern aufbewahrt. Ich erhielt zu diesen Experimenten verschiedlene Male Blut, welches Personen, die an leichten rheumatischen oder entzündlichen Erscheinungen erkrankt waren, durch Schröpfen entzogen worden war. Das Blut wurde bei einer Temperatur von durchschnittlich $5^{0} \mathrm{C}$. aufbewahrt und täglich untersucht. Hier stellte sich wiederholt heraus, dass Proben, welche auf dem heizbaren Objecttische bis $38^{n} \mathrm{C}$. erwärmt wurden, nach Verlauf von 5 und 6 Tagen noch bewegliche farblose Blutkörperchen enthielten.

Die Versuche welche von $K u ̈ h n e^{1}$ ), von mir $^{2}$ ) und von $S a c h s^{3}$ ) in letzter Zeit über die obere Temperaturgrenze angestellt wurden, bei welcher contractile Substanzen und speciell das Protoplasina thierischer und pflanzlicher Gewebe ihre Contractilität und ihr Leben einbuissen, haben übereinstimmend das Resultat ergeben, dass diese

1) Reichert u. Du B ois-Reymond, Archiv für Anatomic, Physiologie etc. 1859, p. 804 . Untersuchungen über das Protoplasma, Leipzig 1864.

2) Das Protoplasma der Rhizopoden und der PAlanzenzellen, Leipz. 1863.

3) Flora 1864, p. 24, 39 ff. 
Grenze zwischen 40 und $50^{\circ} \mathrm{C}$. gelegen sei. Verschiedene Organismen verhalten sich gegen diese hohen Temperaturen etwas verschiedell. Ich bestimmte den Temperaturgrad, welcher tödtet, für Amoeben und Actinophrys auf $43^{n} \mathrm{C}$., für Anguillulinen, Turbellarien und Räderthiere auf $4 \bar{\jmath}^{n}$, für das Protoplasma der Zellen von Urtica, Vallisneria und Tradescantia auf $45-48^{n}$. Diese Bestimmungen sind sämmtlich in Wasser vorgenommen. $\mathrm{S}$ a ch s bewies sodann, dass eingewurzelte Pflanzen von Nicotiana, Cucurbita, Zea Mais, Mimosa pudica, Tropaeolum u. A., welche in $\mathrm{Lu}$ ft erwärmt worden, $25 \mathrm{Mi}$ nuten lang selbst $49-51^{\circ}$ ertragen können; dass aber jede Erwärmung auf $51^{\circ}$ und darüber schnell tödtlich wirkt. Auch die Beobachtung, welche F. Cohn an den Organismen der heissen Quellen von Carlsbarl anstellte, stimmen überein, in so fern $\mathrm{Cohn}$ angiebt, dass das Wasser nach seinen Messungen sich immer erst unter $43^{n} \mathrm{R}$. abkühle, ehe Oscillarien in demselben vorkommen ${ }^{1}$ ). Mit dem Eintreten der letalen Wirkung verändert sich das Protoplasma in einer Weise, welche $K \ddot{\text { üh }} \mathrm{n}$ e für die contractilen Substanzen überhaupt als Wärmestarre bezeichnet, und welche für die Froschmuskeln bei $45^{n}$, für die Muskeln der Sangethiere bei $.9-50^{n}$, bei Vögeln sogar erst bei $53^{n} \mathrm{C}$. in ihrer vollkòmmenen Entfaltung beobachtet wird. Niedere Grade der Starre, welche $\mathrm{K}$ ü h n e der Todtenstarre vergleicht und welche wohl ganz allmählig in die höheren übergehen, treten bei den Froschmuskeln schon bei $40^{n}$, bei Warmblütern einige Grade später auf. Diesen letzteren entspricht, was $K \ddot{u} h n$ e am Protoplasma der Amoeben, Actinophrys, Myxomyceten und der Pflanzenzellen ${ }^{2}$ ) mit dem Namen Wärmetetan us belegt, ein Zustand, den auch Sa chs bei Pflanzenzellen genauer beobachtete ${ }^{3}$ ) und vor übergehende Wärmestarre benennt, dadurch characterisirt, dass das Protoplasma vor dem Eintritt des Todes seine Bewegungen einstellt, unter Abschnürung von Kugeln mannigfache. Formveränderungen eingeht, aber bei der Abkïhlung wieder in den normalen Zustand zurückkehrt.

Diesen an verschiedenen Organismen und Protoplasmagebilden angestellten Versuchen entsprechen nun ganz die Veränderungen, welche man bei einer gesteigerten Temperatur an den farblosen Blutzellen des Menschenblutes beobachtet. Während die Bewregung derselben bei 45 und $46^{\prime \prime}$ noch eine lebhafte, oft sogar gesteigerte ist,

1) Ueber die Algen des Carlsbader Sprudels, Breslau 1863.

2) Kühne, Protoplasma p. 45, 67, 87, 103.

3) 1. c. p. $39,66 \mathrm{ffi}$. 
nimmt dieselbe bei weiterer Zunahme der Temperatur ab. Die Körperchen schicken noch einzelne Fortsätze aus und ziehen sie ein, aber die kriechenden Bewegungen hören auf, die Fortsätze selbst haben ein eigenthümlich zerfliessliches Aussehen, endlich wird das Körperchen starr in irgend einer Form, die dasselbe gerade angenommen hatte. Diese Veränderung sah ich auf dem warmen Objecttisch bei $50-51^{\prime \prime} \mathrm{C}$. eintreten. Natïrlich hängt auch hier viel von der Schnelligkeit des Heizens ab. Denn eine Temperatur von 48 bis $4 ! 9^{n}$, wenn sie länger als 5 Minuten anhält, tödtet unter den gleichen Erscheinungen. Jedenfalls darf als sicher angenommen werden, dass $50^{n}$ ziemlich genau diejenige Temperatur bezeichnet, durch welche die farblosen Blutkörperchen definitiv abgetöltet, $\mathbf{l}$. h. in einen Zustand von bleibender Starre versetzt werlen, und dass dieser letzteren ein Zustand der Bewegungslosigkeit vorausgeht, von welchem die Körperchen sich wieder erholen kömnen, und den wir als vorübergehendle Wärmestarre, nach $K$ üh ne als Wärmetetanus zu bezeichnen hätten. Dieselben Temperaturgrade also, welche bei Süugethiermuskeln die bleibende Starre erzengen, die den Tod des Gewebes kennzeichnet, $49--50^{\prime \prime}$, und nach Obigem überhaupt die obere Grenze darstellen, über welche hinaus das Leben der wichtigsten Bestandtheile des menschlichen und thierischen Körpers, ebenso der Pthanzen, dauernd nicht erhalten werden kann, sind es, welche anch die Contractilität und Integrität einer farblosen Blutzelle nicht iiberdanert.

Ich gehe nach diesen die Natur der farbiosen Blutkörperchen des Menschen betreffenden Mittheilungen zu dem über, was man an den $\mathrm{r}$ o th en Blutkörperchen auf dem heizbaren Objecttisch beobachten kann. Hier muss ich zunächst gleich hervorheben, dass während der lebhaft kriechenden Bewegungen der farblosen Zellen die rothen Körperchen keine Spur von Gestaltveränderung zeigen. Klebs berichtet ${ }^{1}$ ), dass die rothen Blutkörperchen des Menschen und mehrerer Säugethiere mbei Erwärmung des Blutes unter Verhinderung der Verdunstung auf Körpertemperatur $\mathrm{z}$ a ckig werden. Derselbe beschreibt die allmähligen Veränderungen, welche die Blutkörperchen eingehen, bis sie eine zackige Form angenommen haben;

1) Centralblatt f. d. medicin. Wissensch. Berlin 1863. No. 54. 
sehr genau, jedoch ohne die Methode, welche er zur Erwärmung anwandte, anzugeben. Das ganze Phänomen fasste er als einen Act selbstständiger Contractilität auf: ndie rothen Blutkörperchen der Säugethiere sind contractile Gebilde, die sogenannte Maulbeerform derselben entspricht dem bewegten, die backschüsselförmige (die Backschüsselform) dem unbewegten Zustande. Das todte Blutkörperchen hat eine Kugelform." Die Anwendung des heizbaren Objecttisches gestattet auf eine sehr vollkommene Weise ein einzelnes Blutkörperchen während schneller oder langsamer Erwärmung der Beobachtung zu unterwerfen. Bei aller auf den Gegenstand verwandten Aufmerksankeit bin ich nicht im Stande gewesen, auch nur ein einziges Mal bei einer Temperatur von $38-40^{\circ} \mathrm{C}$. eine Gestaltveränderung an einem scheibenförmigen Blutk örperchen zu constatiren. Jedes Blutpräparat birgt gewöhnlich einige zackige Formen, die sich bei Anwendung des geheizten Objecttisches auch in einzelnen Stellen vermehren, doch wo die Verdunstung ausgeschlossen ist, wie unter dem Deckgläschen in der feuchten Kammer, erhalten sich die scheibenförmigen Körperchen auch auf dem $38^{\circ}$ warmen Objecttisch stundenlang unverändert. Ich habe dann Schröpfblut vom Menschen und ganz frisch aus der Ader gelassenes Blut vom Hunde in Reagenzgläschen auf 38,40 und $45^{\circ} \mathrm{C}$. im Wasserbade erwärmt und Proben davon unter das Mikroskop gebracht, aber nie eine Bestätigung der K lebs'schen Angaben erhalten. Es ist somit aus dem Verhalten der rothen Blutkörperchen bei Körperwärme auch kein Grund zu entnehmen, dieselben für contractile Gebilde zu erklären. Der Unterschied zwischen den contractilen, bewegten, farblosen Blutzellen und den regungslos liegenden rothen Blutkörperchen springt vielmehr so in die Augen, dass es gerathener erscheint, zunächst den Gedanken, dass die Substanz der rothen Blutkörperchen mit contractilem Protoplasma etwas gemein habe, aufzugeben.

Die Temperatur, bei welcher die rothen Blutkörperchen des Menschen- und Thierblutes Veränderungen eingehen, liegt höher als die Körpertemperatur, sie fällt mit derjenigen zusammen, bei welcher die contractilen Substanzen in bleibende Wärmestarre gerathen, also den Tod erleiden. Steigert man die Wärme des heizbaren Objecttisches auf etwa $52^{\circ} \mathrm{C}$., so verändern sich die rothen Blutkörperchen des Menschen unter den Augen des Beobachters in einer bisher unbeachtet gebliebenen, sehr charakteristischen Weise. Das Blutscheibchen, welches bis dahin kreisrund, mit napfförmiger Vertiefung, 
kurz in ganz unverändertem Habitus verharrte, erhält jetzt an seinem Rande erst seichte, dann tiefe Einschnürungen in grösserer oder geringerer Zahl, und in wenigen Sekunden sind sümmtliche Blutkörperchen des Präparates total verïndert (Fig. 14). Aus den Einkerbungen entstehen schnell kuglige Abschnürungen, die sich entweder sofort ablösen oder, wie gewöhnlich, eine Zeit lang wie an feinen Stielen untereinander in Zusammenhang bleiben. Die Blutkörperchen theilen sich in eine grössere oder geringere Zahl von kugligen Stücken, unter denen meist das eine central gelegene das grösste ist, gewissermaassen der kuglig gewordene Rest des Blutscheibchens, die anderen grösser und kleiner, bis zu molekularer Kleinheit herab, dem Hauptstück anhängen oder sich ablösen und in lebhafter Tanzbeweyung in der Bluttlüssigkeit vertheilen. Das endliche Resultat dieses Theilungsprocesses ist, dass in der Blutflüssigkeit nur noch kleine Kügrelchen von ziemlich dunkler Blutkörperchenfarbe übrig sind, deren grösste immer noch kleiner als ein ohne Abschnürung kuglig gewordenes Blutscheibchen sind, die kleinsten sich wie Elementarkömchen verhalten. Dazwischen liegen alle möglichén Uebergïnge (Fig. 16).

Ein so einfaches Bild gewährt die Bluttlüssigkeit jedoch erst nach Verlauf einer geraumen Zeit. Gleich nach der Erwärmungr auf $52^{\circ}$ und nach dem Auftreten der ersten eben beschriebenen Veränderungen beobachtet man eine Reihe auf die sonderbarste Weise missgestalteter Blutkörperchen (Fig. 15). Ihre Bildung beruht auf verschiedenen Veränderungen. Statt der Abschnürung von Kugeln zieht sich das Scheibchen in einen langen Cylinder aus, der zunïchst von gleichmässiger Dicke, später knopfförmig angeschwollene Enden erhält. Oder es bilden sich mehrere hintereinander gelegiene Anscìwellungen an demselben veränderten Blutkörperchen aus. Solche Formen können als ein variköser Faden auch von vorneherein aus der Einkerbung und Streckung des Blutscheibchens ihren Ursprung nehmen und kommen bis zu grosser Feinheit und mit zehn bis zwanzig hintereinander liegenden Varikositäten, also wie eine Perlschnur gestaltet, vor. Andere Blutkörperchen treiben statt kugliger Höcker lange Fäden hervor, meist nur einen, der dann bei grosser Länge und bedeutender Feinheit an der lebhaften, durch die Hitze gesteigerten Molekularbewegung theilnehmend, schlängelnde Bewegungeu ausführt. Solche Fäden reissen dann nicht selten $a b$, und indem sie sich fortdauernd bewegen, rücken sie oft den Vibrionen ähnlich in der Flüssigkeit voran. Aus der anfünglich enormen Mannigfaltigkeit 
der Formen gehen dann allmählig immer mehr regelmässig kuglige Bildungen hervor, bis nach Verlauf von einer viertel oder halben Stunde die Blutflüssigkeit das Ansehen wie in Fig. 16 angenommen hat. Diese Veränderung tritt ein, das Blut mag auf der hohen, 50 übersteigenden Temperatur längere Zeit erhalten oder gleich nach der Erwärmung wieder bis zu Zimmertemperatur abgekühlt worden sein.

Alles dies lässt sich ebenso an grösseren Blutmengen beobachten, wenn dieselben im Reagenzglase im Wasserbade erwärmt werden. Ich benutzte Blut, welches verschiedenen Personen durch Schröpfen entleert und 12-24 Stuniten bei circa $5^{\circ} \mathrm{C}$. aufbewahrt worden war. Bei drei auf diese Art untersuchten verschiedenen Blutproben traten die beschriebenen Veränderungen sofort auf, nachdem das Plut eine Temperatur von $50-52^{n} \mathrm{C}$. angenommen hatte. Die $\mathrm{Me}$ thode bietet den Vortheil vor der Erwärmung auf dem heizbaren Objecttisch, dass man die Greuze, bis zu welcher man die Temperatur steigern will, viel genauer einhalten kann. Daher gelingt es mittelst derselben leicht, die verschierlenen Stadien der Veränderung zu fixiren, also z. B. sämmtliche Blutkörperchen nur bis zum Auftreten der Einkerbungen und Einschnürungen des Randes zu erwärmen, aber die Abschnürung der Theilstücke noch aufzuhalten, welche dann bei geringer Temperatursteigerung sofort eintritt.

Ich bemerke hier beiläufig, dass die Beobachtung dieser Umwandlung eine gute und sehr bequeme Probe für den heizbaren $\mathrm{Ob}$ jecttisch abgiebt, welche sich den im Eingange beschriebenen, auf der Bestimmung des Schmelzpunktes von Fetten beruhenden an die Seite stellt. Treten bei langsamem oder schnellerem Heizen die Abschnürungen der Blutscheibchen bei etwa $52^{\circ} \mathrm{C}$. auf, so wird man sich auf die Uebereinstimmung im Gange des Thermometers und der Temperatur des Präparates verlassen können.

Die Versuche, welche ich mit menschlichem Schröpfblut unternahm, dehnte ich auf einen Zeitraum von mehreren Tagen nach dem Ablassen des Blutes aus, um zu entscheiden, wie lange nach der Entleerung aus den Gefässen die Blutkörperchen die Fähigkeit zu den beschriebenen, bei circa $52^{\circ} \mathrm{C}$. eintretenden Veränderungen behalten. Bekanntlich verlieren die rothen Blutkörperchen ausserhalb des Körpers allmählig ihre Napfform und werden kuglig. Je nach der Temperatur, bei welcher man das aus der Ader gelassene Blut aufbewart, tritt die Umwandlung früher oder später ein. Das Re- 
sultat meiner Versuche war nun, dass mit dem Auftreten dieser Umwandlung die Fähigkeit zu den characteristischen Wärmeveränderungen verloren geht. Die Blutkörperchen bleiben kuglig auch bis zu einer Temperatur von $60^{\circ}$ und darüber, bis sie Gerinnungserscheinungen zeigen. So lange jedoch die Napfform erhalten ist, schnüren sie sich auch bei $52^{n}$ in Stücke. Ein Tropten Blut aus der Fingerspitze unter Deckglas 2--3 Stunden bei $40^{\circ} \mathrm{C}$. in der feuchten Kammer aufbewahrt, enthält meist keine napfförmigen Blutkörperchen mehr, und die höhere Temperatur bringt keine Abschnürungen hervor. Schröpfblut, welches dagegen bei $3-5^{\circ} \mathrm{C}$. in einem Glase 8 T a ge lang gestanden hatte, enthielt noch viele, meist münzenförmig gruppirte, unveränderte Blutkörperchen, welche sich gegen die Steigerung der Temperatur ganz wie frische verhielten.

Einige vergleichende Versuche, welche ich an Blutscheibchen von Thieren anstellte, ergaben für die warmblütigen Thiere, wie sich voraussetzen liess, eine grosse Uebereinstimmung mit dem Blute des Menschen. Ich benutzte von Säugethieren, Kaninchen, $\mathrm{Hund}, \mathrm{Ka} \mathrm{lb}$ und Meerschweinchen. Das Blut dieser'Thiere, mag es frisch aus der Ader gelassen oder inehrere Tage bei niederer Temperatur aufbewahrt worden sein, veründert sich bei einer Wärme über $50^{n} \mathrm{C}$. wie das des Menschen. Es schnüren sich von der Peripherie der Blutscheibchen kleinere und grössere Kügelchen ab, welche frei herumschwimmen, während der übrigbleibende Theil auch kuglig wird. An frisch aus der Ader gelassenem geschlagenem $\mathrm{Hundeblut}$ machte ich im Wasserbade einige genauere Temperaturbestiminungen, welche ergaben, dass eine Erwärmung des Blutes bis 50 und $51^{\circ}$ noch keine Veränderung in der Gestalt der rothen Körperchen erzeugt, wenn, wie in meinen Versuchen geschah, die hohe Temperatur nicht länger als 5 Minuten constant einwirkte. Sowie aber $52^{\circ}$ erreicht sind, erhalten die Blutkörperchen Einkerbungen, und zwischen 52 und $53^{\circ}$ tritt sofort die Abschnürung der durch Einkerbung begränzten Randpartieen ein, und der Rest des Blutkörperchens nimmt Kugelform. an. Das Gleiche beobachtete ich sodann am Blute des Huhnes, doch bedurfte es hier einer Temperatur von $53-54^{\circ}$, um die merkwürdigen Veränderungen hervorzurufen. Von kaltblütigen Thieren verglich ich bis jetzt nur den Frosch, und zwar Exemplare, welche im Monat Februar, also während des Winterschlafes, im Freien gesammelt worden waren. Die rothen Blutkörperchen erhielten sich bis $43^{\circ}$ C. unverändert, darüber hinaus erwärmt nahmen viele die 
Form von Löffelbiscuit oder Dumbbellform an, so zwar, dass die angeschwollenen Enden dunkel gefürbt, die mittlere schmale Brüeke fast farblos erschien. Dabei trat aus fast allen Blutkörperchen eine grössere Zahl molekulär kleiner Körnchen aus, von denen sich nicht deutlich unterscheiden liess, ob sie gefärbt waren oder nicht. Einzelne hingen in Reihen und Fäden zusammen und alle zeigten lebhafte Molekularbewegung. Ein Abschnïren grösserer Tropfen oder Kugeln, wie es die Wärmeveränderung der Blutkörperchen der warmblütigen Thiere auszeichnet, beobachtete ich beim Frosch auch dann nicht, wenn die Temperatur bis 55 und $60^{\circ}$ gesteigert wurde. Es tritt eine körnige Gerinnung im Blutkörperchen, aber keine weitere Gestaltänderung ein. Jedenfalls ist das Verhalten analog dem der Blutkörperchen warmblütiger Thiere, doch darin verschieden, dass die Veränderung, schon bei $45^{\circ} \mathrm{C}$. eintritt und zu keiner so vollständigen Zerstörung der Blutkö̀perchen führt.

B e al e, welcher, wie oben angeführt wurde, auch Blut erwärmte, hat, nach seinen Abbildungen zu schliessen ${ }^{1}$ ), offenbar dieselben Umwandlungen der rothen Blutkörperchen gesehen. Doch geht er oberflächlich über die Beobachtung hinweg und bestimmte nicht einmal. den Temperaturgrad genauer, bei welchem die Veränderungen eintreten, beschränkt sich vielmehr auf die Angabe mbei mässiger Hitze (etwas über $100^{\circ}$ )“. Nach Fahrenheit aber, dem B eale wohl unzweifelhaft folgt, sind $52^{\circ} \mathrm{C}$. ungefähr gleich $127^{\circ}$. Sehr zu verwundern ist, dass die beschriebenen Veränderungen $R$ oll et entgangen sind, dem wir so bemerkenswerthe Aufschlüsse über die $\mathrm{Na}$ tur der rothen Blutkörperchen verdanken, und der, wie oben erwähnt, bei Gelegenheit seiner Untersuchungen über den Einfluss, welchen electrische Schläge auf das Blut ausüben, auch einiger Beobachtung'en über Wärmeveränderungen am Blute gedenkt. Rollet hat die so merkwürdige Theilung der Blutkörperchen, das Abschnüren von Fäden und Kügelchen nicht gesehen, obgleich er sowohl mittelst eines freilich sehr unvollkommenen warmen Objecttisches, als auch mit Hülfe des Wasserbades arbeitete. Er beschreibt als endlichen Effect nur das Kugligwerden der Blutscheibchen, und verweist bezüglich der ersten Veränderungen auf seine Angaben über den, Einfluss der electrischen Schläge, durch welche auch nur Formveränderungen, aber keine Theilungen entstehen sollen. Für die Säugethierblutkörperchen

1) Quart. Journal of microscop. science No. XIII, 1864, Pl. VI, Fig. 2, 3. 
verlegt er den Eintritt dieser Gestaltverïnderung auf $40-45^{\circ} \mathrm{C}$. In der That werden die Blutkörperchen des Menschen wie der Süugethiere endlich kuglig, wenn sie st unden lang auf dieser Temperatur, sei es auf dem warmen Objecttische oder im Wasserbade, erhalten werden; man würde aber sehr irren, wenn man daraus schliessen wollte, dass die Temperatur von $40-45^{\circ}$ an sich diesen deletären Effect auf die Blutscheibchen ausübe. Schon daraus, dass diese hohe Temperatur innerhalb der im Leben vorkommenden Grenzen liegt, ergiebt sich die Unhaltbarkeit dieses Schlusses. Die aus dem Körper entfernten Blutscheibchen werden, längrere Zeit aufbewahrt, bei jeder Temperatur über dem Gefrierpunct kuglig, bei $40-45^{\circ}$ aus nahe liegenden Gründen nur viel schneller als bei $4-5^{n}$. Mit einem eigenthümlichen, plötzlich auftretenden Temperatureinfluss, wie (der von mir beschriebene es ist, haben wir es dabei nicht zu thun. Um diesen zu beobachten muss eine Erwärmung bis mindestens $50^{\circ} \mathrm{C}$. eintreten.

Aber noch in einer anderen Beziehung befinde ich mich in einer Differenz mit Rollet. "Niemals (, sagt derielbe ${ }^{1}$ ), mgelingt es, (lurch 'Temperatursteigerung dem Blute die Transparenz und Durchsichtigkeit des electrisirten Blutes zu geben." Nach meinen zuerst auf dem warmen Objecttisch ausgeführten, dann im Wasserbade controllirten Versuchen lösen sich bei ungeführ $60^{\circ} \mathrm{C}$. die kleinen und grossen kugligen Theilstücke der Blutkörperchen auf, d. h. es entsteht eine lackfarbene Lösung von Hämoglobin von bekanntem Aussehen. In dieser Lösung schwimmen die entfärbten und daher schwer sichtbaren Reste des $\mathrm{Str}$ o ma der Blutkügelchen, wie bei einer wässerigen Lösung die sogenannten "Membranen der Blutzellen،. Durch Alcohol oder Jodlösung können dieselben deutlich gemacht werden. Und dass das Hämoglobin in Lösung übergegangen ist, ohne zersetzt zu sein, beweist seine noch erhaltene Krystallisationsfähigkeit. Ich habe die Beobachtung gemacht, dass Blut vom Meerschweinchen, welches auf dem heizbaren Objecttisch über $60^{\circ}$ erwärmt und dadurch in eine lackfarbene Lösung verwandelt worden war, beim Erkalten und bei langsamer Verclunstung auf dem Objectträger sofort krystallis irte. Ich nahm dann grössere Blutmengen desselben Thieres in's Wasserbad, ebenfalls bis zu einer Temperatur von mindestens $60^{\circ} \mathrm{C}$, und sah dann

1) 1. c. p. 15 . 
jeden Tropfen dieses Blutes bei Verdunstung zu einem dichten Krystallbrei erstarren. Nach längerem Stehen der so veränderten Blutproben bei kühler Temperatur schied sich das Hämoglobin in grösseren Krystallen aus. Das Blut vom Kalb, Kaninchen und vom Menschen in gleicher Weise behandelt, krystallisirte beim Eintrocknen oder beim längeren Stehen $\mathrm{nicht}$, obgleich die Lösung eine ebenso vollständige war. Ich habe es bisher unterlassen, weitere Versuche über die Gewinnung von Krystallen aus solchem durch Wärme in Lösung gebrachten Hämoglobin anzustellen, zweifle aber nicht, dass dieselben in ähnlicher Weise zum Ziele führen werden, wie sie mit Lösungen gelingen, die durch Gefrieren des Blutes nach Rollet ${ }^{1}$ ) erhalten werden.

Ich kann nicht unterlassen, bei dieser Gelegenheit zu betonen, wie verwandt der Einfluss niederer, unter $0^{\circ}$ gehender, und höherer, $50^{\circ}$ übersteigender Temperaturgrade auch beim Blute sich herausstellt, wie solches für andere Gewebe namentlich von $\mathrm{K} u \mathrm{hn}$ e und S a chs hervorgehoben worden ist. Die Blutkörperchen werden durch Frost kuglig und das Hämoglobin tritt in Lösung gerade so, wie durch den Einfluss einer Wärme von $50-60^{\circ} \mathrm{C}$. Die Abschnürungen und Theilungen der Blutkörperchen, welche ich bei den successive eintretenden Temperatursteigerungen beobachtete, sind bei Kältewirkung bisher freilich nicht zur Wahrnehmung gekornmen, vielleicht nur desshalb nicht, weil man es unterliess, ein einzelnes Blutkörperchen während des Gefrierens genan zu verfolgen. Ich verweise hier noch auf die Versuche von Sachs über das Erfrieren von Pflanzen $^{2}$ ) und die Controllversuche bei höheren Temperaturgraden ${ }^{3}$ ), sowie anf Kứ hne's Untersuchungen über den Einfluss der Kälte auf die Staubfadenhare von Tradescantia ${ }^{4}$ ).

Bei Betrachtung der merkwürdigen Gestaltveränderungen, welche die rothen Blutkörperchen des Menschen und der Thiere bei einer Temperatur ïber $50^{\circ} \mathrm{C}$. eingehen, werden wir sofort erinnert an ähnliche Umwandlungen, denen nach Kölliker's Beobachtung die rothen Körperchen des Froschblutes unterliegen, wenn sie mit

1) Sitzungsber. d. Akad. d. Wiss. zu Wien Bd. 46. Versuche und Beobachtungen arn Blute.

2) Berichte der Königl. Sächsischen Gesellschaft der Wissenschaften $\nabla$. J. 1860.

3) Flora 1864, p. $71 \mathrm{ff}$.

4) Protoplasma p. 101. 
concentrirter Harnstofflösung in Berührung kommen. Preyer hat neuerlichst diese Beobachtungen wiederholt und Abbildungen zu denselben geliefert ${ }^{1}$ ), welche, wie seine Beschreibung, beweisen, dass dabei im Wesen ganz gleiche Formänderungen vorkommen, wie sie durch die höheren Temperaturgrade hervorgerufen werden. Aber auch ganz spontan können die Blutkörperchen des Frosches derurtige Veränderungen ihrer (Gestalt eingehen, wie $R$ ind fl $\mathrm{e}$ is $\mathrm{ch}^{2}$ ) und Preyer gezeigt haben, und diese Beobachtungen sind für eine Deutung der Vorgänge auch in den Säugethierblutkörperchen von besonderer Bedeutung.

Es handelt sich dabei wesentlich un zwei die Natur der rothen Blutkörperchen betreffende Fragen. Sind dieselben mit einer vom Inhalte verschiedenen $\mathrm{K}$ embran ausgerüstet, und haben wir Ursache, der Substanz der genannten Körperchen Contractilität zuzuschreiben? Beide Fragen sind erst in der neuesten Zeit aufgeworfen worden, und vor der Hand wohl kaum entscheidend zu beantworten. Zunächst ist zu berücksichtigen, dass Mensch, Süugethiere und Frosch, an denen man an meisten experimentirte, sich durchaus nicht in allen Beziehungen gleich verhalten. Es kann wohl kaum einem Zweifel unterliegen, dass die rothen Blutscheibchen des Menschen und der Siugethiere, wie ich schon früher hervorhob ${ }^{3}$ ), aus einer voin Protoplasma contractiler Zellen so durchgreifend verschiedenen Substamz bestehen, dass, da ihnen zugleich ein K e r n fehlt, der Name "Zelle«, mit dem sie vielfach belegt werden, ihnen nicht zukommt. Da nun weiter von mir oben nachgewiesen worden, dass an den rothen Blutkörperchen Erscheinungen von Contractilität bei Temperaturen, die sonst zur Hervorrufung von Gestaltveränderungen ausserordentlich geeignet sind, nicht zur Beobachtung gelangen, so wird man anstehen, diejenigen Umwançllungen, welche sie bei einer Temperatur über $\check{5} 0^{\circ} \mathrm{C}$, , die nachweislich den Torl jedes contractilen Gewebes zur schnellen Folge hat, eingehen, ohne Weiteres einer lebendigen Contractilität zuzuschreiben. Anders verhält es sich mit den Froschblutkörperchen. Ihnen kommt nicht nur ein Ker n zu, sondern auch die Substanz derselben scheint, wie namentlich $\mathrm{He}$ se ${ }^{4}$ ) hervorhob, zum Theil noch dem Protoplasma, also der con-

1) Virchow's Arehiv XXX, Taf. XV, Fig. $35 \mathrm{a}-\mathrm{g}$.

2) Experimentalstudien über die Histologie des Blutes, Fig. 1 e.

3) Ueber Muskelkörperchen etc. p. 23.

4) Zeitschrift f. wissensch. Zoologie Bd. XI, 1861, p. 253.

II. Schultae, Irehur f, mhilosit. Anatomie. I. Bd. 
tractilen Substanz derjenigen Zellen ähnlich oder gleich, aus welchen sie bei der Entwickelung hervorgingen. Wenn wir bei solchen Zellen Gestaltveränderungen ablaufen sehen, wie sie Preyer so ausführlich beschrieben und abgebildet hat, so werden wir uns auch seiner Deutung, dass es sich hier um eine der Contractilität des Protoplasma analoge Erscheinung handle, anschliessen können. Freilich dürfen wir labei nicht ausser Acht lassen, dass es gerade absterbende, in Extravasatblut enthaltene und entschieden ihrer endlichen Auflösung entgegengehende Körperchen waren, an denen diese Beobachtungen vorzugsweise gemacht wurden, und dass demnach auch noch nach einer anderen Seite hin ein Ausweg bleibt. Nehmen wir dazu die Versuche Rollet's über den Einfluss electrischer Schläge auf die rothen Blutkörperchen, aus denen dieser mit Blutuntersuchungen so vertraute, gewandte Forscher Gründe abnimmt, der Klebs'schen Ansicht von der Contractilität der rothen Blutkörperchen auf das entschiedenste entgegenzutreten, so wird zugegeben werden müssen, dass zunächst der tiefgreifende Unterschied zwischen Zellen-Protoplasma und Substanz eines rothen Blutkörperchens nur befestigt erscheint. Was aber die Frage nach der Existenz einer Membran auf der OberHäche der rothen Blutkörperchen des Menschen betrifft, so stehe ich keinen Augenblick an, mich auf die Seite von Brücke und Rollet 1) zu stellen, welche hervorheben, dass kein haltbarer Grund zur Annahme einer solchen vorliege. Rollet's Versuche durch mechanische Eingriffe Blutkörperchen in alle mögliche Gestalten und zur Theilung. zu bringen, und die Thatsache, dass jedes Theilstück sofort Kugelform annimmt, lassen sich so wenig mit der Existenz einer vom Inhalt des Blutkörperchens verschiedenen Membran vereinigen, dass es kaum noch der neuen Angriffe gegen die Membran bedarf, welche wir aus dem Verhalten der Blutkörperchen bei $50^{n} \mathrm{C}$. und darüber entnehmen. Die Art wie das Blutscheibchen bei dieser Temperatur sich in Stücke theilt, die sich alle sofort in Kugeln umwandeln, und die nicht etwa blos Tropfen einer Flüssigkeit sind, sondern, wie die Behandlung mit Wasser zeigt, aus einem Stroma und einer Hämoglobinlösung bestehen, gerade so, wie das unveränderte Blutkörperchen, ferner die proteisch verschiedenen Gestalten, welche

1) Brücke, die Elementarorganismen. Sitzungsber. d. Akad. d. Wiss. zu Wien 1861, Bd. 44, p. 388 . Rollet, Versuche und Beobachtungen am Blute. Ebenda Bd. 46. 
die Blutkörperchen bei $52^{n}$ annehmen können, von denen unsere Figg. 14 und 15 eine Anschaung geben: alles dies bildet inmerhin ein äusserst belehrendes unl äberzeugendes Object, wenn es sich um Beurtheilung des eigenthümlichen Aggregatzustandes der Blutkörperchen handelt, und muss schwer ins Gewicht fallen, wenn die Gründe für und wider eine Membran gegen einander abgewogen werden sollen.

Was hier uher das Verhalten der rothen Blutkörperchen berichtet wurle, bezieht sich alles auf die gewöhnliche Form derselben, auf die bekannten scheibenförmigen Körperchen. Ich bin aber nicht der Ansicht derer, welche meinen, dies sei die einzige Form rother Blutkörperchen beim Menschen. Ich finde in dem meinigen und in dem Blute einiger anderer Personen constant eine geringe und nach den 'I'ageszeiten schwankende Zahl kleiner, kugliger, rother Blutkörperchen (Fig. 2) von 0,005-0,006 Mm., und von diesen allmählige Uebergünge zu den gewöhnlichen scheibenförmigen von 0,008 bis 0,010 Mm. Durchmesser. Dieselben betheiligen sich nicht an der geldrollenförmigen Gruppirung der Blutscheibchen. und sind also, wie die farblosen, in den Zwischenräumen zwischen den Rollen zu finden. Einige haben ein Ansehn wie feinzackig, andere wie feingranulirt, wozwischen oft schwer zu entscheiden ist. Dem berechtigten Verdacht gegeniber, dass diese kleinen und kugehunden Körperchen erst nachträglich auf dem Objecttrïger entstanden seien, muss ich anführen, dass ich mich durch möglichste Vorsicht und Schnelligkeit in der Anfertigung der Präparate sowohl vor Verdunstung als vor Beimischung von Sekret der Schweissdrüsen u. dergl. m. zu schützen suchte. Immerhin gebe ich zu, dass ein vollgültiger Beweis für ihre Präexistenz im kreisenden Blute fehlt, und unterlasse ich es daher hier auch, auf die zahlreichen in der Literatur verzeichneten Angaben und die Meinungsverschie(lenheiten über diese Körperchen einzugehen, über welche ein endgültiges Urtheil fällen zu können ich mich bisher vergeblich bemüht habe. Wenn schon im gesunden Zustande des Blutes die Neigung der scheibenförmigen Körperchen kuglig $\mathrm{zu}$ werden sehr gross ist, so nimmt dieselbe, wie mich $\mathrm{zu}$ überzeugen ich mehrfach Gelegenheit hatte, bei starkem Fieber bedeutend zu, daher Aderlass- und Schröpfblut, wenn es nicht sofort zu mikroskopischen Präparaten verwandt wird, nur mit grösster Vorsicht zu Schlüssen in dieser Richtung benutzt werden darf. Das Blut einer an embolischer Pneumonie erkrankten Wöchnerin, welches ich aus Fingern und dem Arm entnahm. konnte 
ich kaum schnell genug unter das Deckgläschen bringen, um scheibenförmige Körperchen zu sehen. Lies ich dasselbe nach der R indfle isch'schen Methode langsam in den capillaren Raum unter das Deckgläschen eintreten, so fand sich der grösste Theil der rothen Körperchen sphärisch umgestaltet, während in einem schnell auf dem Objectträger aufgefangenen und sofort mit dem Deckgläschen bedeckten Tropfen die Zahl der sphärischen viel geringer war. Aderlassblut derselben Kranken, welches noch vor dem Gerinnen in eine enghalsige Flasche gefüllt -war, die mir zugestöpselt durch die Güte meines Collegen Ve it sofort zukam, enthielt 1-2 Stunden nach dem Aderlass, zu welcher Zeit ich die erste Untersuchung vornahm, sehr viele kleine sphärische Blutkörperchen. Ueber das Blut dieser Kranken habe ich sonst nur zu berichten, dass sich dasselbe ungemein reich an farblosen Elementen zeigte ${ }^{1}$ ), welche alle der feingranulirten Form angehörten, dass es aber andere fremdartige Bestandtheile der mikroskopischen Untersuchung nicht darbot, auch nur sehr arm an den gleich noch zu erwähnenden, normal oft sehr reichlich im Blute enthaltenen Körnchenbildungen war.

Im Blute ist gewiss kein Bestandtheil gleichgültig und so will ich denn zunt Schluss nachdrücklichst auf einen bisher fast ganz unbeachtet gelassenen, dennoch normalen Formbestandtheil des menschlichen Blutes aufmerksam machen. Ich finde in meinem und dem Blute zahlreicher anderer darauf untersuchten Personen mittleren und jugendlichen Alters mehr oder minder reichlich unregelmässig gestaltete $\mathrm{Klümpchen} \mathrm{farbloser} K \ddot{~} \mathrm{gelch}$ en, von sehr verschiedener Grösse, je nachdem sie aus wenigen oder vielen Kügelchen zusammengesetzt sind. Die letzteren messen einzeln höchstens 0,001-0,002 Mm., und kommen auch einzeln im Blute vor, viel häufiger sind sie zu locker zusammenhängenden, nicht scharf umschriebenen Gruppen vereinigt, in denen eine feinkörnige Masse sie untereinander verklebt. So finde ich sie zu 3, 4, aber auch zu 30 und mehr, unter Umständen zu hunderten vereinigt, deren. Plaques dann bei ganz unregelmässiger Gestalt einen längsten Durchmesser von

1) Den Reichthum an farblosen Körperchen beobachtete auch $S \operatorname{chult} \theta \mathbf{n}$ im Blute einer an Puerperalfieber Erkrankten (Virchow's Archiv Bd. XIV, 1858, p. 503). Ich habe denselben in höchst auffallendem Grade bei einer zweiten an Thrombose leidenden Wöchnerin constatirt, welche später genas. Vor allen Dingen wird natürlich der im Wochenbette normale Zustand festzustellen sein, ehe diesen vereinzelten Beobachtungen ein Werth beigelegt werden kann. 
$0,08 \mathrm{Mm}$. und darüber haben können. Die Kügelchen selbst sind ganz farblos, homogen oder wenig feinkörnig und in der Art ihrer Lichtbrechung von der umgebenden Blutflüssigkeit nur wenig unterschieden, daher blass und schon ihrer geringen Grösse wegen, welche 6-8 mal geringer als die der rothen Blutkörperchen ist, nur mit guten starken Linsen einzeln zu erkennen. Aber nicht immer stellen sie regelmässige Kugeln dar, oft sind sie eckig verzogen, besitzen dann meist etwas schärfere Contouren und auch ein deutlicher körniges Ansehn. Auch die Gruppen derselben brechen das Licht schwach und sind nur in sehr dünn ausgebreitetem Bluttropfen gut zu sehen. Farbige Elemente sah ich sie nie einschliessen, auch eine Beziehung $z u$ den farblosen Blutkörperchen vermochte ich nicht aufzufinden. Die Gebilde machen ihrer unregelmässigen Gestalt und Grösse wegen und nach ihrer ganzen Bildung aus verschieden grossen blassen Körnchen entschieden den Eindruck im Zerfall befindlicher Gewebstheile. Aber ihr Ursprung ist noch nicht erforscht. Am wahrscheinlichsten könnte man halten. dass sie aus zerfallenen farblosen Körperchen der feingranulirten Form hervorgegangen seien. Doch bleibt dies ungewiss, so lange wir über das endiche Schicksal dieser und der anderen farblosen Körperchen des Blutes im Dunkeln sind. Ihr Verhalten gegen Reagentien bestätigt die aus ihrem Ansehn zu gewinnende Vermuthung, dass sie aus einer dem Protoplasma der Zellen verwandten Eiweisssubstanz bestehen. In Wasser quellen die grösseren Körnchen deutlich an, und werden zu sehr blassen, hellen Kugeln, in verdünnter Essigsäure erhalten sich die Plaques längere Zeit, werden aber im Ganzen sehr durchsichtig, wobei jedoch einzelne der grösseren Kügelchen unter Schrumpfung etwas schärfere Contouren annehmen. In verdünnter Kalilauge verschwinden sie vollständig. Auch im schnell getrockneten Blute lassen sie sich deutlich erkennen. und werden jetzt weder von Alcohol noch Aether angegriffen. Aber die Masse der Kügelchen oder der Zwischensubstanz dem l eb e n di g en Protoplasma an die Seite zu stellen, dazu liegt kein bestimmter Grund vor. Denn, was das wichtigste ist, die Fähigkeit zu spontaner Gestaltveränderung geht diesen Bildungen ab. Ich habe weder bei Zimmer- noch bei Körpertemperatur auf dem warmen Objecttische Bewegungen an ihnen wahrnehmen können. Sie erhalten allerdings unter Umständen das Ansehn, als wenn Strahlen feinkörnigen Protoplasmas von ihnen ausgingen, ähnlich wie bei der von mir beschriebenen Amoeba porrecta des Mittelmeeres. Aber diese Erscheinung 
hängt nur mit der Gerinnung des Faserstoffes zusammen. Indem die Körnchenhaufen von den feinen Fäden des unter dem Deckgläschen gerinnenden Blutes eingeschlossen werden (vergl. Fig. 18), ziehen viele Fäden durch die Körnchenhaufen hindurch. Auch gewinnt es oft den Anschein, als wenn die Gerinnung von den letzteren ausginge. Jedenfalls sind die Strahlen keine Fortsetzungen der körnigen Masse selbst, sondern nur Fïden geronnenen Faserstoffes.

Liegt es nach dem Vorgebrachten näher, die fraglichen Gebilde für Produkte einer Gewebsautlösung, für Detritusbildungen, als für entwicklungsfïhige Elementartheile zu halten, so stehe ich doch an, einen auf diese rückschreitende Metamorphose deutenden Namen ihnen schon jetzt beizulegen, und ziehe einen indifferenten, nach keiner Seite präjudicirlichen, nämlich »Körnchenbildungen « vor. Indem ich diese Bezeichnung hier einführe, muss ich aber sofort an die mannigfachen anderen "Körnchen" erinnern, welche schon im Blute beobachtet und vielfach erwähṇt sind. Namentlich wären dreierlei Bildungen hier ins Auge zu fassen, welche zum Theil mit unseren Körnchenbildungen zusammenfallen oder verwechselt sein mögen. Als ein häufigerer Bestandtheil der Blutflüssigkeit werden namhaft gemacht Elementarkörnchen fettiger Natur. Von diesen sagt Kölliker (Mikroskopische Anatomie p. 575 und Handbuch der Gewebelehre 1863, p. 624), dass sie mit denen des Chylus vollkommen übereinstimmen, d. h. ") unmessbar feine Körnchen sind, die wie H. Müll er gezeigt hat, aus Fett und einer Hülle eines Eiweisskörpers bestehen, und im milchweissen Chylus, dessen Farbe sie alle in bedingen, in ungeheurer Zahl enthalten sind, während sie in der mehr farblosen Lymphe entweder ganz fehlen oder nur spärlich und vereinzelt auftreten. I Im Blute "finden sie sich in sehr wechselnder Zahl, bald sehr spärlich oder gar nicht, bald in grösserer selbst ungeheurer Menge, so dass sie dem Serum eine weissliche, selbst milchweise Farbe ertheilen. Nach Allem was wir wissen, müssen sich dieselben jedesmal, wenn durch den Chylus Fett in das Blut übergeführt wird, tinden, also auch bei ganz gewöhnlicher Nahrung 3-6 Stunden und länger nach der Aufnahme derselben, scheinen jedoch in vielen Fällen während des Durchgehens des Blutes durch die Lungen zu schwinden, indem wenigstens $\mathrm{Nasse}$ (Wagners Handwörterb. I, p. 126) u. A. bei gesunden Leuten in Körperblute dieselben stets vermissten, was ich selbst für mein Blut bestätigen kann«. Es handelt sich hier um Fettkörnchen von starker Lichtbrechung, welche in irgend erheb- 
licher Menge in der That selten im Blute vorzukommen scheinen. Mir sind dergleichen bisher noch nicht aufgefallen. Eine Verwechselung mit unseren Körnchenbildungen ist aus doppeltem Grunde kaum anzunehmen, einmal wegen der ganz verschiedenen Art der Lichtbrechung, und dann desshalb, weil die Fettkörnchen stets einzeln, unsere Körnchen dagegen fast immer in kleineren orler grösseren Gruppen vereinigt vorkommen. Eine grosse Aehnlichkeit dürften unsere Körnchenplaques dagegen haben mit den von Kölliker'zu den maussergewöhnlichen oder selteneren Bestandtheilen des Blutes « gerechneten ${ }^{1}$ ) mblissen feinkörnigen, rundlichen Haufen im Blute der Milzvene (F unke) und im Blute der Milz und und Leber bei säugenden Thieren (ich). Im letzteren Falle sind es 0,01-0,02"' grosse, nicht scharf umschriebene Massen, deren Körnchen in Wasser bis zu $0,0005-0,0008^{\prime \prime \prime}$ aufquellen. Dieselben vergehen in Kali rasch und in Essigsäure nach und nach, werden dagegen von Aether und Alcohol nicht angegriffen und scheinen demzufolge vorzüglich aus einem leicht löslichen Eiweisskörper zu bestehen (. Es scheint mir kaum zweifelhaft, dass es sich hier um verwandte Bildungen handelt, die denn also nach meinen Untersuchungen als allgemeiner im Blutstrom verbreitet anzusehen sind, wenn auch bei verschiedenen Individuen variirend und vielleicht in derjenigen Grösse und Menge, wie das Milz- und Lebervenenblut sie beherbergt, in anderen Körpergegenden nicht oder nur ausnahmsweise vorhanden. Endlich muss ich der $\mathrm{Z}$ i mmermann'schen "Elementar körperchen “ gedenken ${ }^{2}$ ), denen trotz wiederholter eindringlicher Gegenvorstellungen seitens ihres Entdeckers $^{3}$ ) das Bürgerrecht versagt geblieben ist. Ob sich Jemand in neuerer Zeit eingehender als Hensen mit denselben beschäftigt hat ${ }^{4}$, ist mir nicht bekannt geworden. Auch dieser Forschev kommt aber wie andere frühere zu dem Resultate, dass diese Elementarkörperchen Kunstprodukte seien, entstanden aus den farblosen und farbigen Blutkörperchen unter Einwirkung der Salzlösungen, welche Zimmerman $\mathrm{n}$ als besonders geeignet empfohlen hat, um in ihnen die in Rede stehenden Körperchen wahrzunehmen.

1) Gewebelehre 4. Aufl. 1863, p. 630 .

2) Rust's Magazin f. d. gesammte Heilkunde Bd. 66 .

3) Virchow's Archiv Bd. XVIII, 1860, p. 221. Zeitsehr. f. wiss. Zoologie Bd. XI, p. 344 .

4) Zeitschr. f. wiss. Zoologie Bd. XI, p. 259. 
In den neueren Handbüchern der Gewebelehre ${ }^{1}$ ) sind dieselben unerwähnt geblieben. Virchow ${ }^{2}$ ) hält ndie von Zimmermann beschriebenen Gebilde für ausgetretenen Inhalt der Blutkörperchen, der in ganz frischem Blute kaum vorkommen dürfte."

Es kann gewiss keinem Zweifel unterliegen, dass die Mischung des Blutes mit den Salzlösungen, welche $Z$ imm e r m a n n empfiehlt, um seine Elementarkörperchen in möglichst reichlicher Menge zu sehen, zu Veränderung der rothen Blutkörperchen Veranlassung giebt, der Art, dass sie klein und kuglig werden wie die grösseren unter den Elementarkörperchen. Die ganze haltlose Hypothese Z i m m e r ma n n's von der U m w and I n $\mathrm{g}$ seiner Elementarkörperchen in farbige Blutbläschen beruht auf dem Mangel einer Unterscheidung solcher künstlich veränderter Blutkörperchen von den kleineren farblosen Gebilden, die normal im Blut vorkommen. Ich habe auch Aderlassblut solcher Kranken, die an Pneumonie litten, untersucht, in denen $\mathrm{Zim-}$ mermann ebenfalls seine Elementarkörperchen besonders reichlich findet, und glaube dass anch hier wie in dem Blute anderer an heftigem Fieber darnieder liegender Kranken die zahlreichen sphärisch gewordenen Blutkörperchen zu Täuschungen Verunlassung gegeben haben. Aber ich kann nicht lüugnen, dass die kleinste n Formen der Z i m m erm a nn'schen Elementarkörperchen, die frühesten Entwickelungsstufen derselben, aus denen dann nach und nach die rothen Blutblüschen werden sollen, unseren "Körnchenbildungen" sehr nahe stehen, und kaum von ihnen verschieden sein dürften. Neben der geringen Grösse und dem Mangel stär.kerer Lichtbrechung sowie dem Verhalten gegen Reagentien stimmt auch die Angabe ${ }^{3}$ ), dass sie noft in Schollen oder Kugelgruppen vereinigt liegen «. Wenn ich also auch einen Theil der Zimmermann'schen Elementarkörperchen als den unsrigen fremdartige Gebilde und wahrscheinlich nachträglich veränderte rothe Blutkörperchen ausscheiden muss, so bleibt doch ein anderer Theil übrig, den ich den geringschätzigen Urtheilen und Angriffen Mancher gegenüber in Schutz nehmen muss, wenn ich auch über ihre Bedeutung anderer Ausicht als $Z$ immermann bin.

Die Körnchenbildungen im Blute des Menschen seien also hiermit allen denen, welche sich eingehender mit dem Blute beschäf-

1) Von Gerlach, Kölliker, Leydig, Frey.

3) Cellularpathologie 3. Anfl. 1862. p. 209.

3) Virchow's Archiv XVIII, p. 229. 
tigen, angelegentlichst empfohlen. Das Material, welches mir vorlag, hat noch keine Anhaltspunkte zur Beurtheilung ihrer etwaigen Bedeutung für pathologische Processe gegeben. Doch ist es vielleicht nicht Zufall, dass ich sie. am allerreichlichsten in dem Blute einer ana emischen Frau, und zwar mehrere Monate constant in gleich grosser Menge gefunden habe.

\section{Erklärung der Tafeln.}

\section{Taf. I.}

Fig. 1. Der heizbare Objecttisch von unten gesehen, in halber natürlicher Grösse. a a, a a Holzleistchen, welche an die Unterseite des messing. nen Objecttisches befestigt sind. Zwischen ihnen liegt in der Mitte der Behailter aus Messingblech für die mit Quecksilber gefüllte Spirale des 'Thermometers;' welche die centrale Blendungsöffnung umkreist; $\mathrm{b} \mathrm{b}$ die beiden Arme, unter welche die Lampen gestellt werden; $\mathrm{c}$ die Skala des Thermometers; ee die Stellen, an welchen die Klemmschrauben am passendsten angebracht werden.

»2. Die v. Recklinghausen'sche feuchte Kammer in der auf dem heizbaren Objecttische von mir benutzten Form.

\section{Taf. II.}

Sämmtliche Figuren dieser Tafel sind bei der gleichen 7-800 mal. Vergrösserung gezeichnet und betreffen nur das Blut des Menschen.

Fig. 1. Rothe Blutscheibchen der gewöhnlichen Grösse.

" 2. Kleine sphärische rothe Blutkörperchen, welche sparsam zwischen den scheibenförmigen vorkommen.

» 3. Kleinste farblose Blutkörperchen, zum Theil mit 2 Kerneu.

\4. Mittelgrosse farblose Blutkorperchen, a. kuglig, b. unregelmässig zackig.

" 5. Grosse feingranulirte farblose Blutkörperchen, a. kuglig, b. zackig.

"6. Grosse grobgranulirte farblose Blutkörperchen, a. kuglig, b. zackig, c. kleinere Form.

" 7. Feingranulirte Form mit einigen starklichtbrechenden kleinen Körnchen, welche den Uebergang der feingranulirten in die grobgranulirte Form bedingen.

* 8. Feingranulirtes farbloses Blutkörperchen bei $38^{\circ} \mathrm{C}$. auf dem geheizten Objecttisch, in lebhaft kriechender Bewegung. Die gezeichneten Formen stellen also ein und dasselbe Körperchen in seinen rasch aufeinander folgenden Gestaltveränderungen dar. 
Fig. 9. Nehrere grobgranulirte farblose Blutkörperchen in ihren bei $38^{\circ} \mathrm{C}$. stattfindenden kriechenden Bewegungen gezeichnet. Die unbezeichneten mit einem Kern und die mit 2 bezeichneten mit $z$ wei Kernen stellen successive aufgetretene Veränderungen je eines Körper. chens dar.

\10. Feingranulirtes Blutkörperchen, welches bei Körpertemperatur Zinoberkörnchen aufgenommen hat.

^11. Ein desgleichen mit Anilinblau gefüttert.

* 12. Ein grobgranulirtes Körperchen, welches Anilinblau aufgenommen hat.

» 13. Ein feingranulirtes Blutkörperchen ans einem mit Vilch verdünnten Tropfen Blut, hat bei Körperwärme 5 Milchkügelehen in sich aufgenommen.

* 14. Rothe Blutkörperchen des Menschen bei $51-52^{\circ} \mathrm{C}$. Aus den links liegenden, noch unveränderten gehen unter Bildung von Einkerbungen und Abschnürungen die anderen Formen hervor.

* 15. Dasselbe Blut, nachdem die Abschnürungen und Gestaltveränderungen sämmtliche Blutkörperchen ergriffen haben.

๖ 16. Dasselbe Blut eine Viertelstunde später. Sämmtliche Blutkörperchen sind in kleinere und grössere kuglige Stücke getheilt.

* 17. Die Kórnchenbildungen, welche normal im Blute des Menschen oft in grosser Menge vorkommen.

- 18 Dieselben, nachdem der Faserstoff des Bluttropfens unter dem Deckgläschen geronnen ist. 
Archiv finicroscov Anatomie BAI.

Iat.

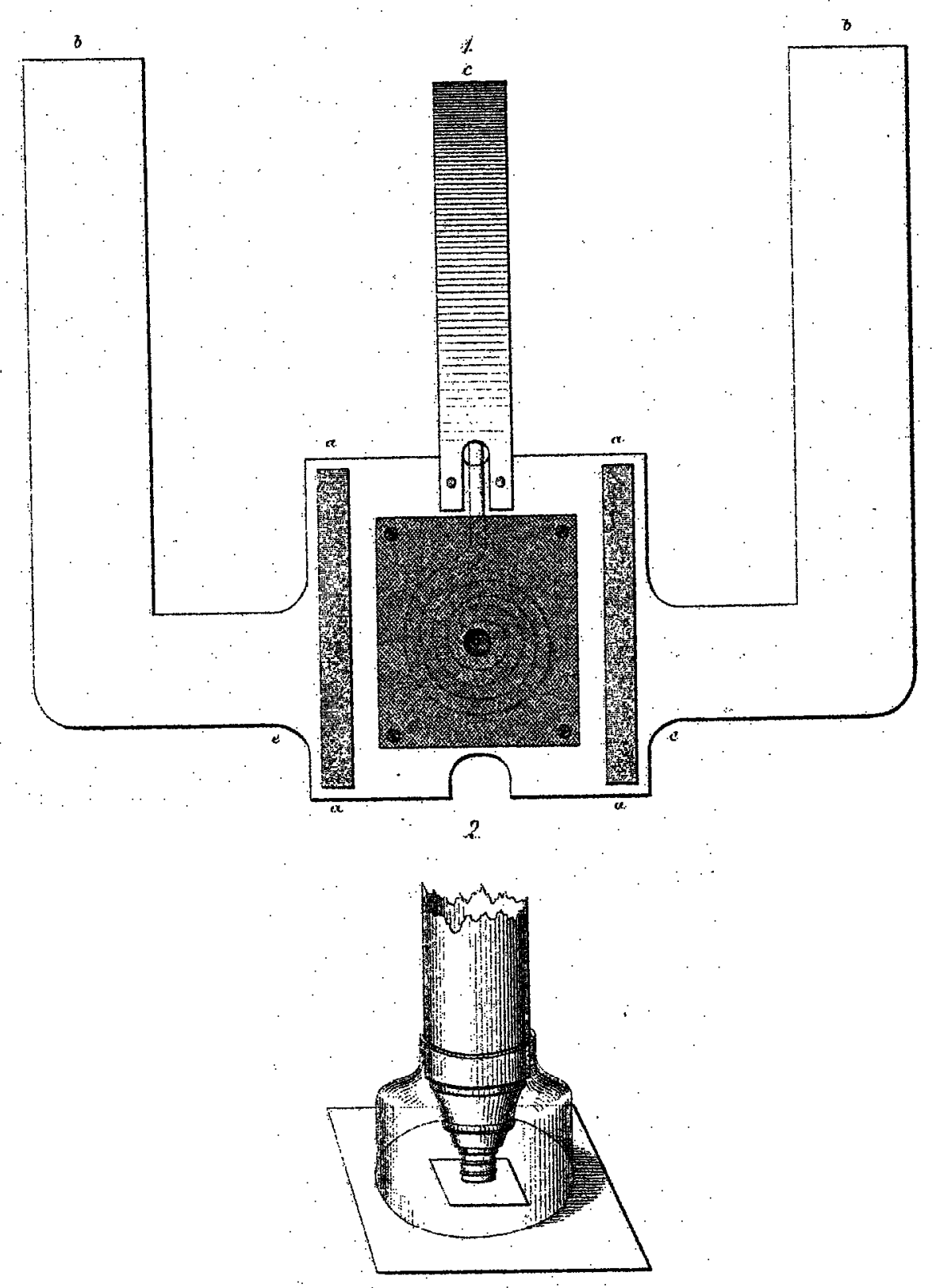

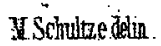

